
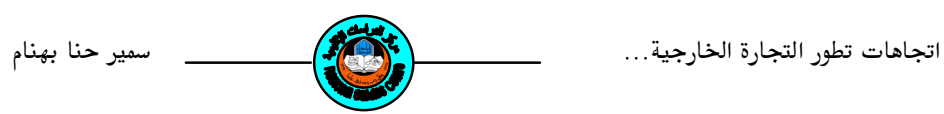

اتجاهات تطور التجارة الخارجية التركية وأثرها في الذمو الاقتصادي للمدة (2009-1990)

\author{
سمير حنا بهنام
}

مدرس مساعد/ قسم الاقتصاد / كلية الإدارة والاقتصاد / جامعة الموصل

مستخلص البحث

تعد التجارة الخارجية المحرك الأساس للذمو الاقتصادي لـدول العـالم المتقدمسة منهـا والناميسة، إذ فئ

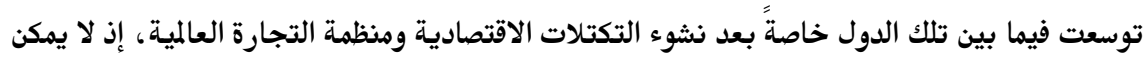

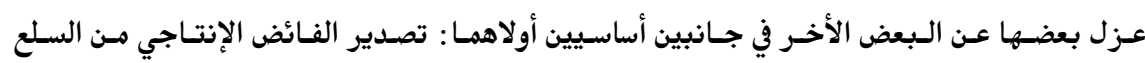

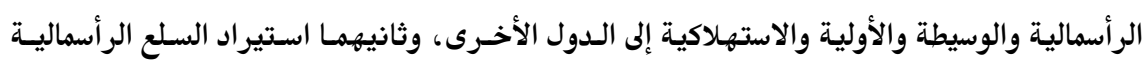

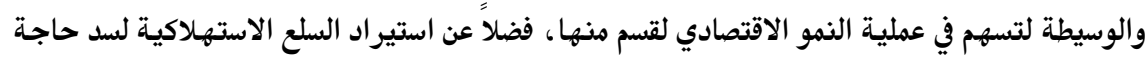
الطلب المحلي المتزايدة خاصة الدول النامية، ويهدف البحـث التعـرف على اتجاهـات تطـور التجـارة

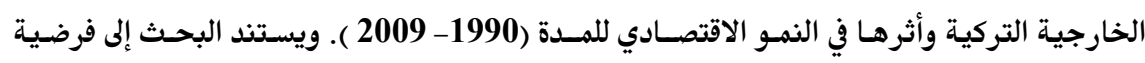

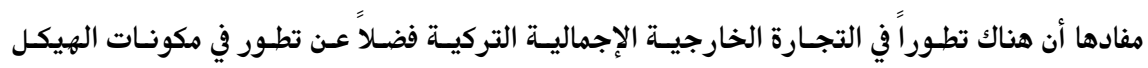

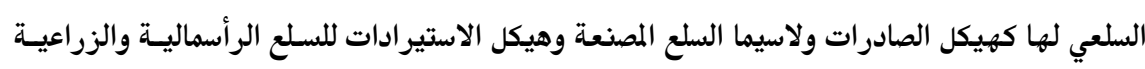

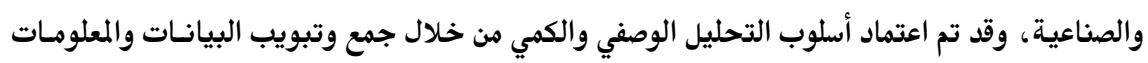
الخاصة بالتجارة الخارجية التركية بالاعتماد على المصادر الرسمية.

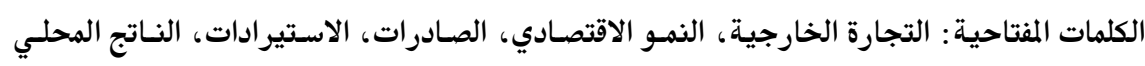
الإجمالي.

مقدمة

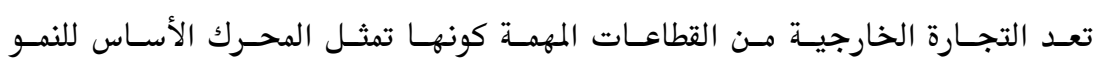

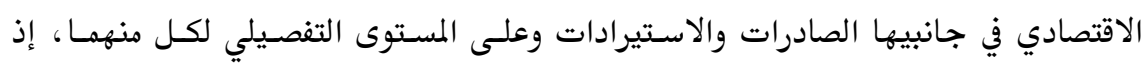

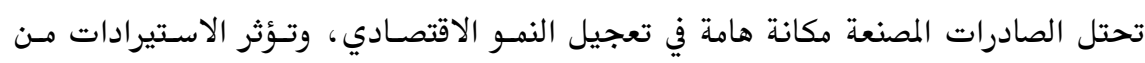


السلع الرأسمالية الصناعية والزراعية بشكل مباشر في تحريك نمو القطاعات السـعية المكونـة

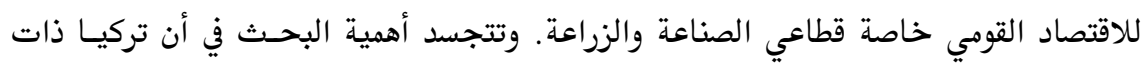

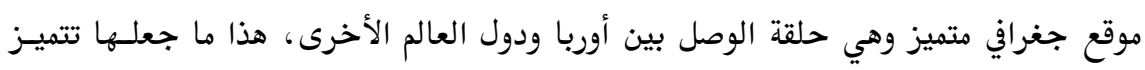

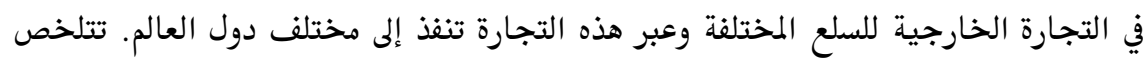

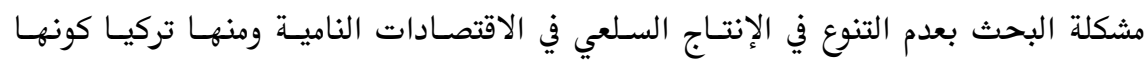

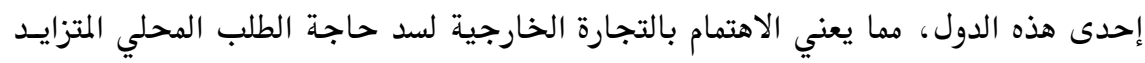

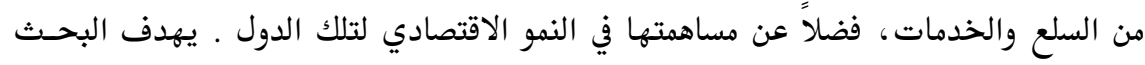
إلى توضيح اتجاهات تطور التجارة الخارجية التركيـة على المستويين الإجمالي والتفصيلي

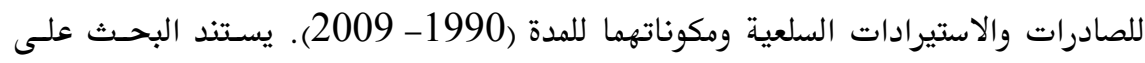

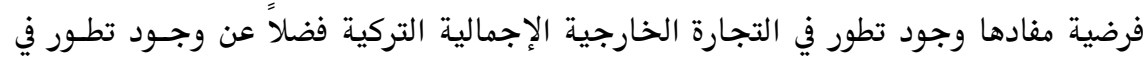

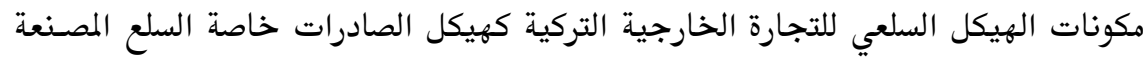

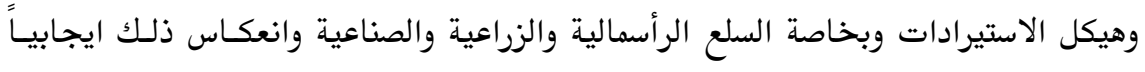

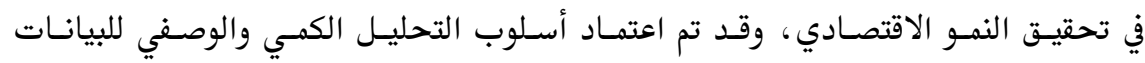

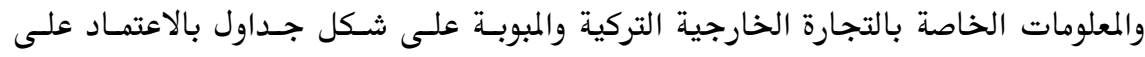

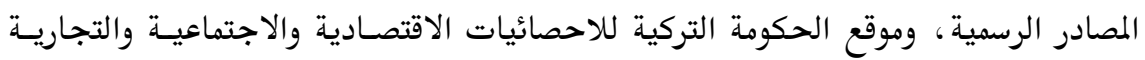

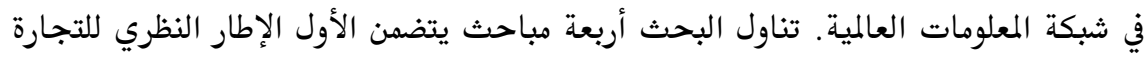

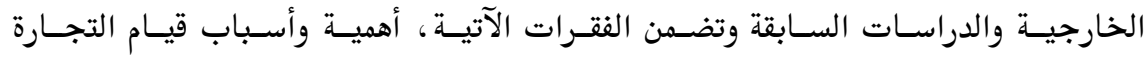
الخارجية، فوائد التجارة الخارجية، العوامل المؤثرة في التجارة الخارجية، نظريات التجارة

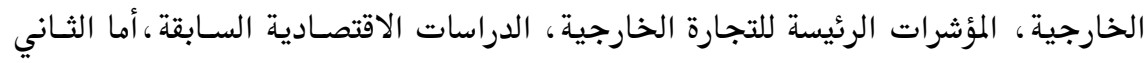

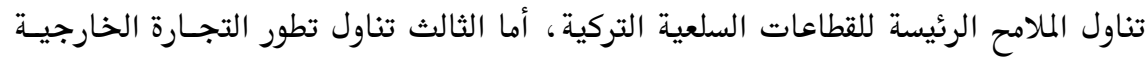

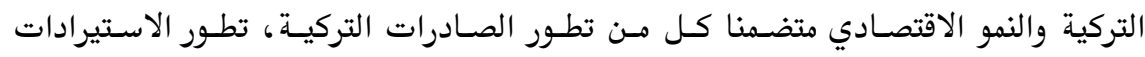

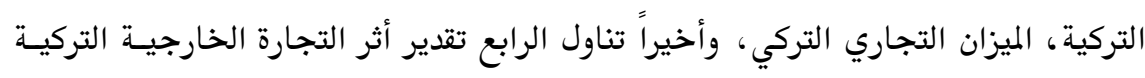

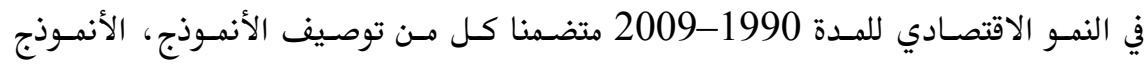

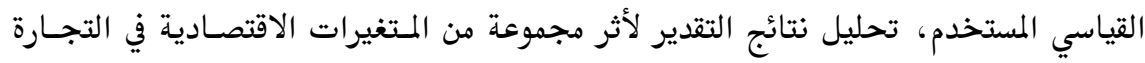




$$
\text { سمير حنا بهنام }
$$

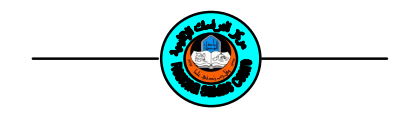

اتجاهات تطور التجارة الخارجية ...

الخارجية التركية للمدة (1990- 2009) فضلاً عن النتائج و والمقترحات ومسن ثـم الخلاصـة باللغة الانكليزية.

\section{المبحث الأول: الإطار النظري للتجارة الخارجية والدراسات السابقة}

1- أهمية التجارة الخارجية: تعد التجارة الخارجية إحدى الركائز الأساسية في الاقتصـاد

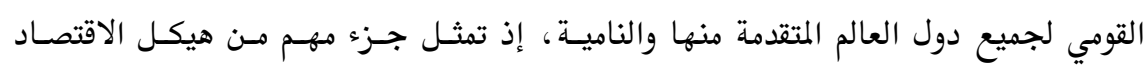

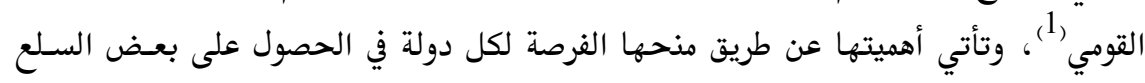

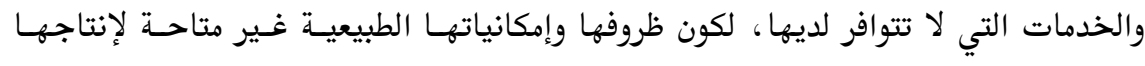

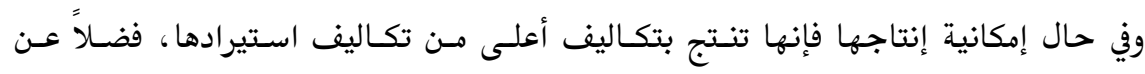

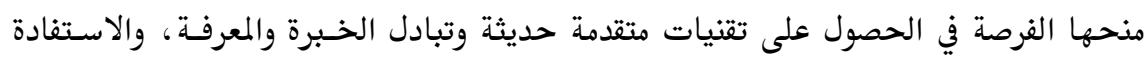

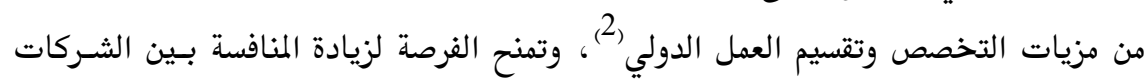

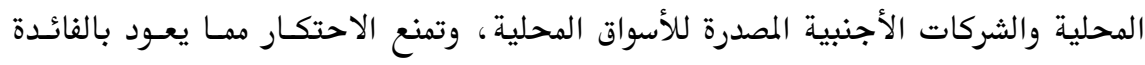

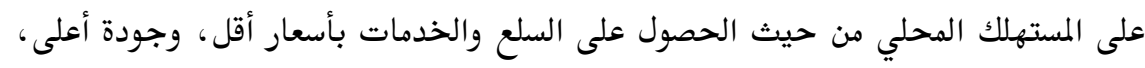

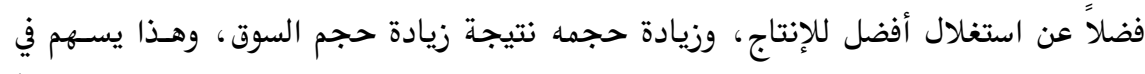

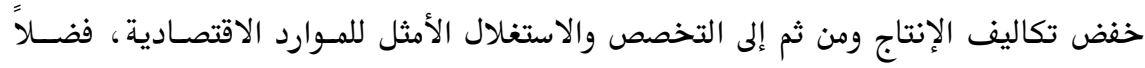

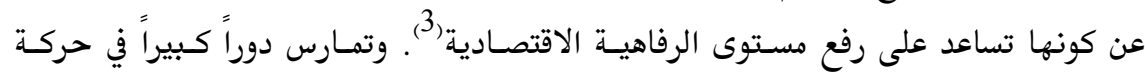

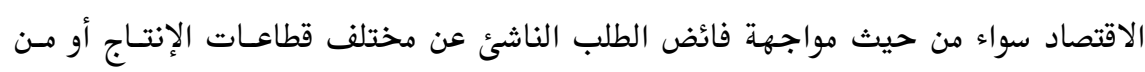

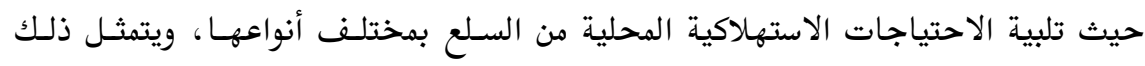

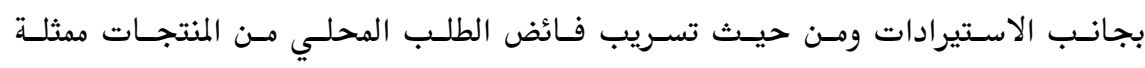

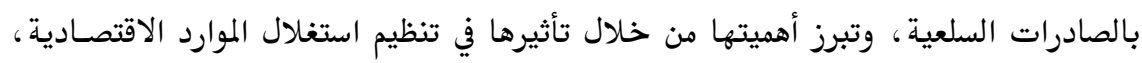

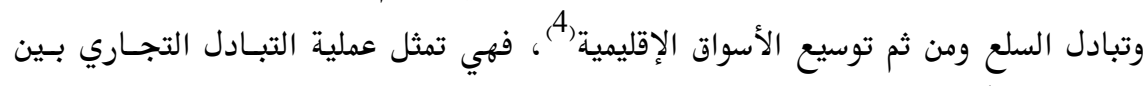

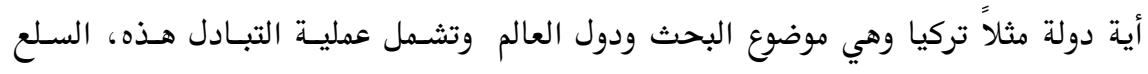

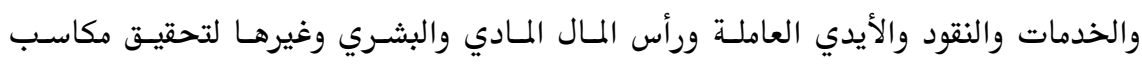

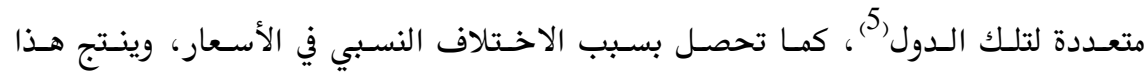


الاختلاف بسبب حدوث التغيرات في الطلب والعرض، واختلاف السعر النسبي يمثل الحافز

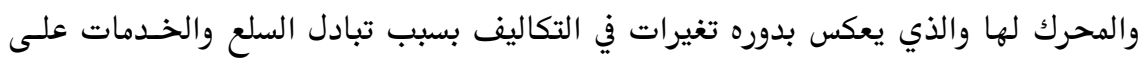

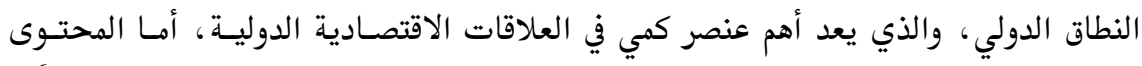
الجوهري الآخر لتلك العلاقات فيشمل حركة الأشخاص ورؤوس الأموال من دولة لأخرى (6).

2- أسباب قيام التجارة الخارجيسة: يمكـن إجمـال أهـم أسـباب قيـام التجـارة الخارجيـة

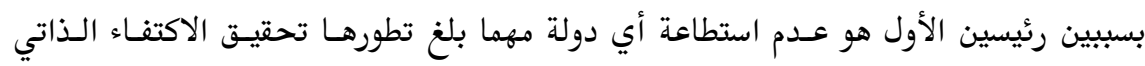

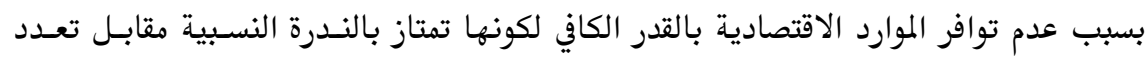

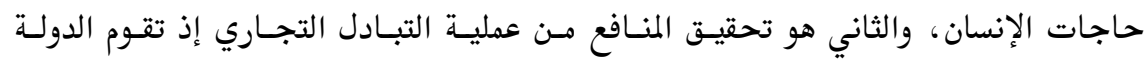

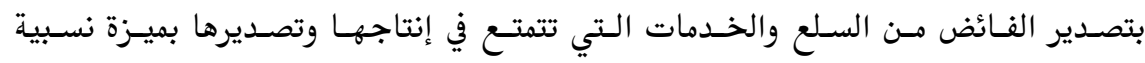

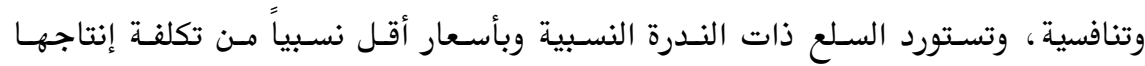

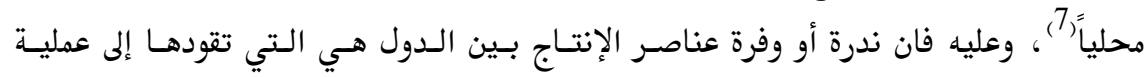

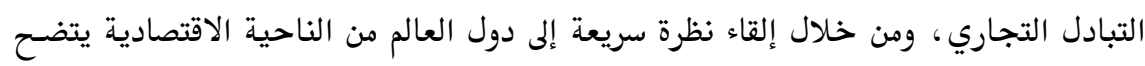

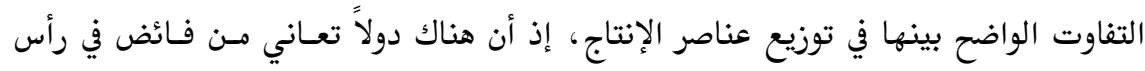

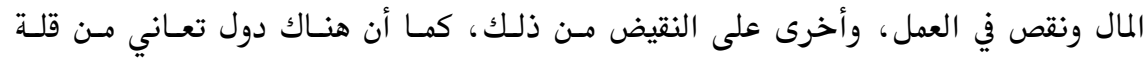

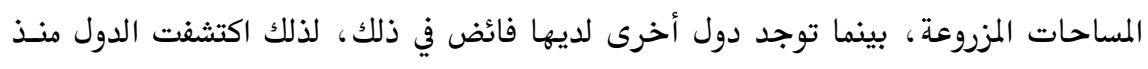

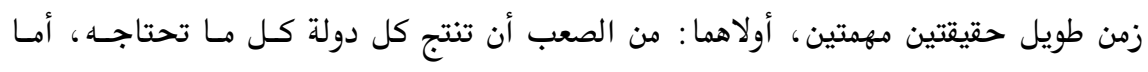

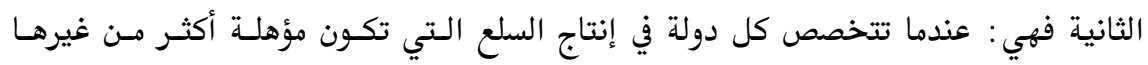

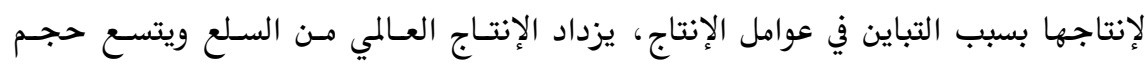

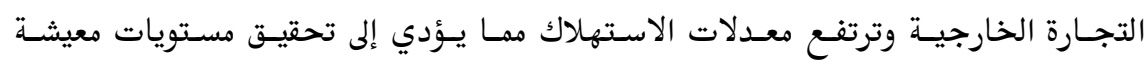
أفضل (8)، فاختلاف المستوى التقني وتباين الأسلوب الإنتـاجي والمعرفـة التقنيسة بـين السدول

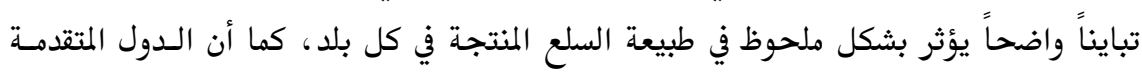

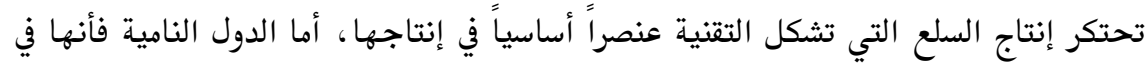

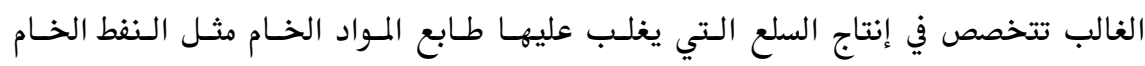

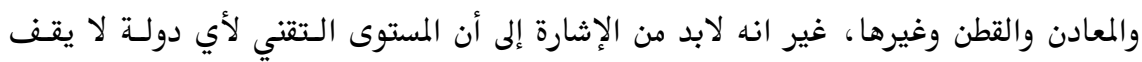



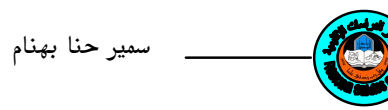

عند حد معين، بل يتغير نتيجة للعوامل السياسـية والاقتصـادية والاجتماعيـة والفكريـة(9)، فالدول المستوردة للتقنية في الوقت الحاضر قد تصبح مصدرة لها كما حدث فئ في اليابان وكوريـا

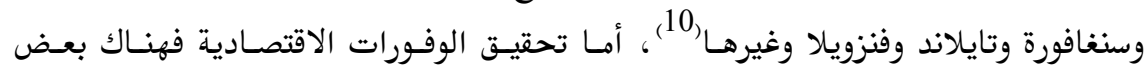

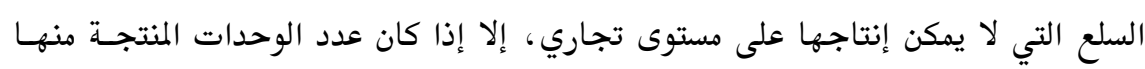

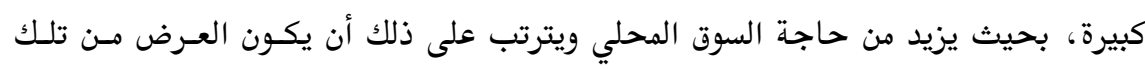

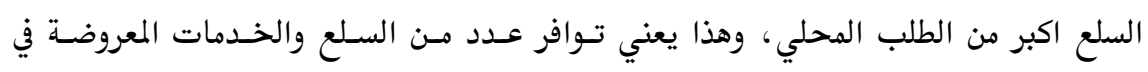

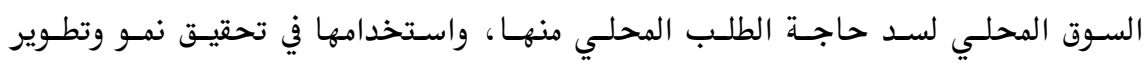
القطاعات السلعية المكونة للاقتصاد القومي. 3- فوائد التجارة الخارجية: يمكن توضيح أهـم فوائسد التجـارة الخارجيـة بزيسادة الرفـاه

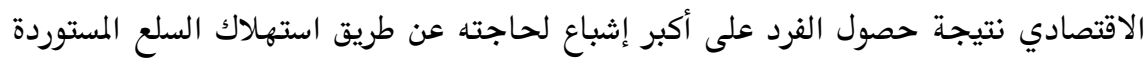

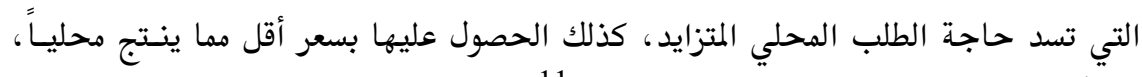

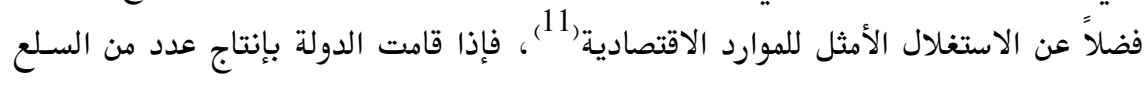

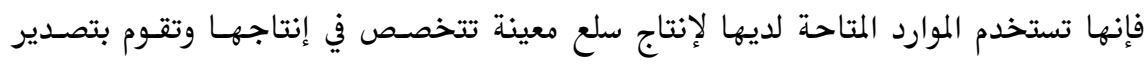

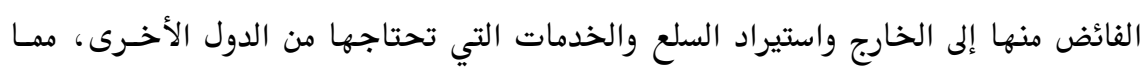

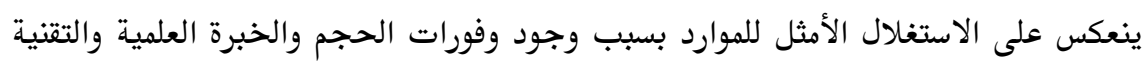
المستخدمة في الإنتاج للسلع والخدمات المختلفة وتحقيق التبادل التجاري بين الدولتين. 4- العوامل المؤثرة في التجارة الخارجية: يمكن عرض أهم العوامل التي لها تأثير في حجم

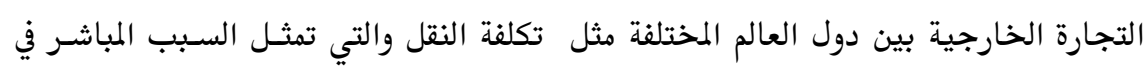

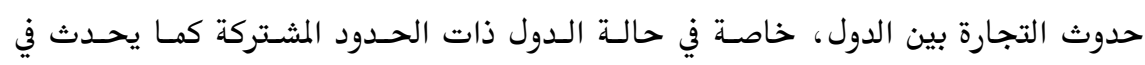

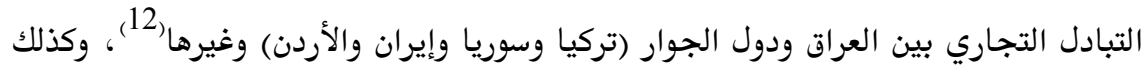

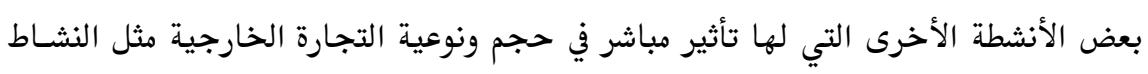

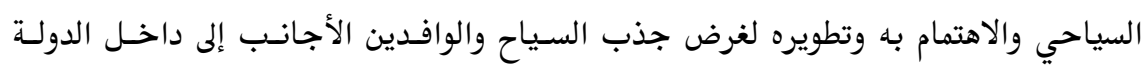

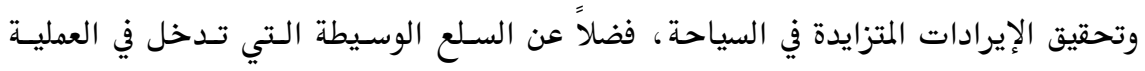


الإنتاجية بهدف إنتاج سلع أخرى، وإنتاجها يتطلب استخدام سلع معينة تؤثر على حجـم أندا

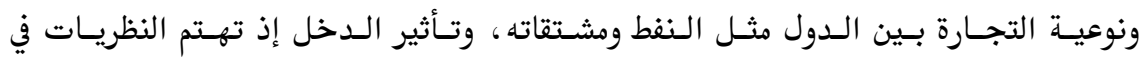

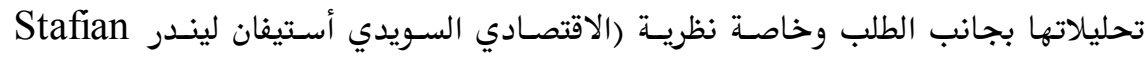

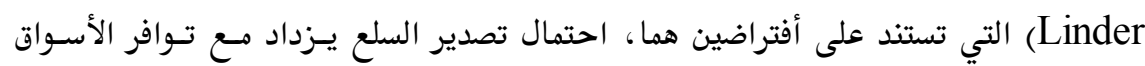

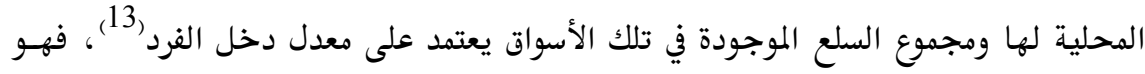

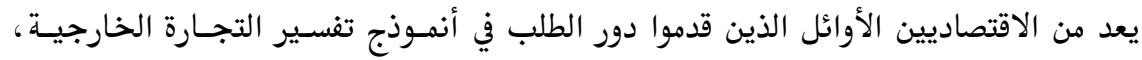

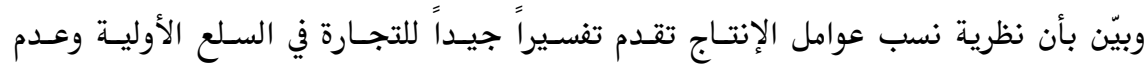

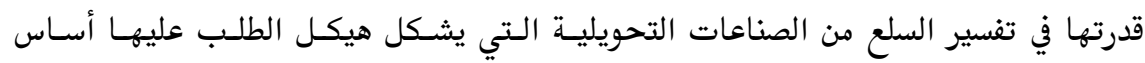

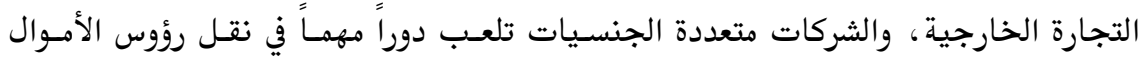

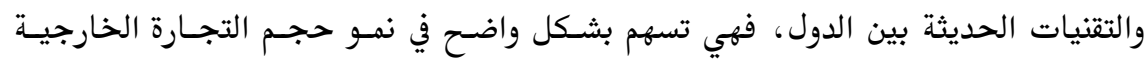

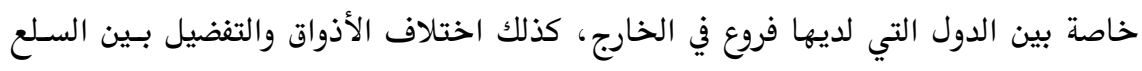

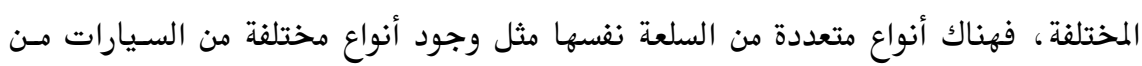

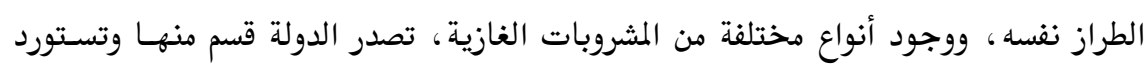
أنواع أخرى مما يؤدي إلى التجارة في هذه السلع. 5- نظريات التجارة الخارجيـة: يـرى بعـض الاقتصـاديين بـان دراسـة نظريـات التجــارة

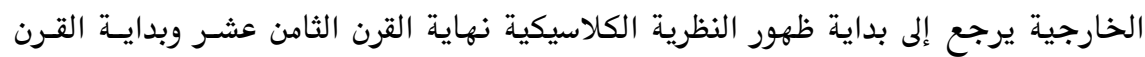

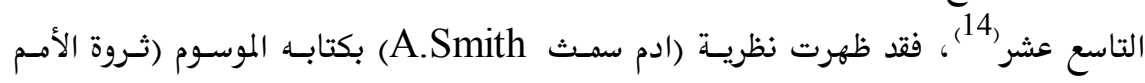
The Wealth of Nations

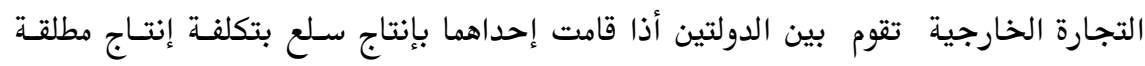

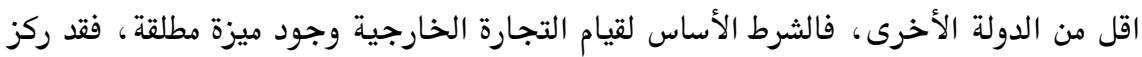

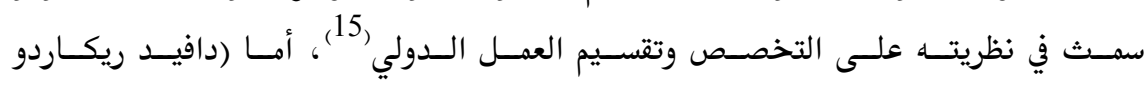

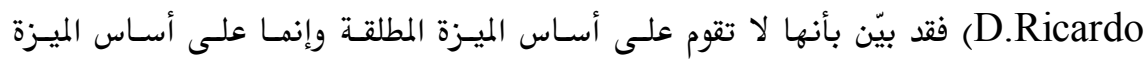

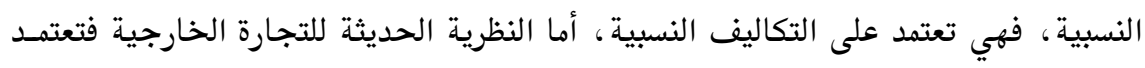

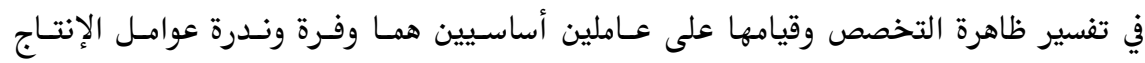



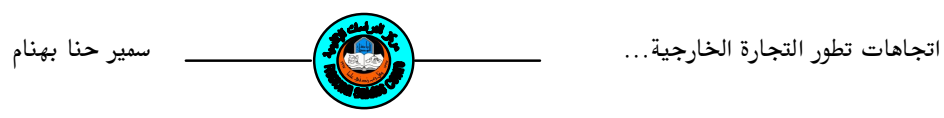

داخل كل دولة وتناقص النفقة وتزايـد الغلـة في حالـة التوسـع في الإنتـاج، إن وفرة ونسدرة

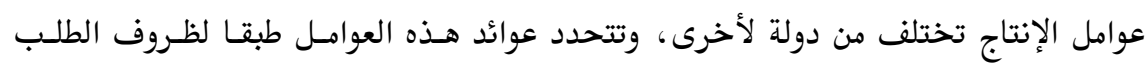

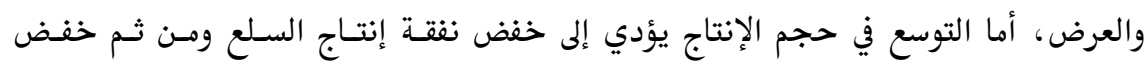

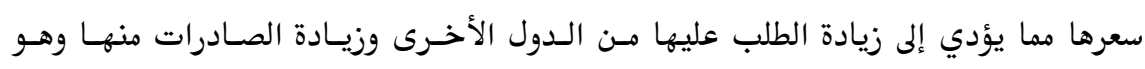

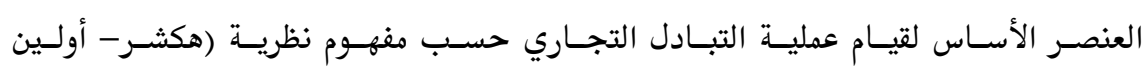
ف Heckscher-Ohlin

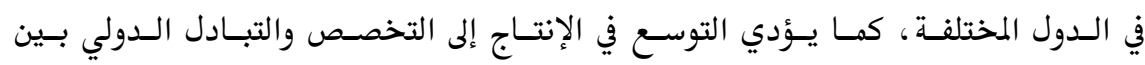
الدول(16) - (16).

6- المؤشـرات الرئيسـة للتجـارة الخارجيـة : إن تحليـل التجـارة الخارجيـة يعـد تحلـيلا

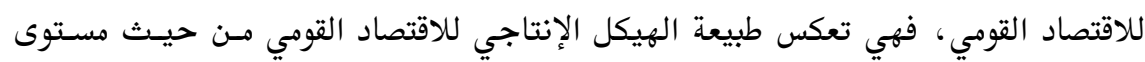

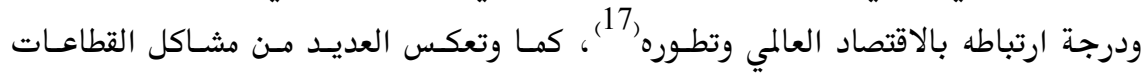

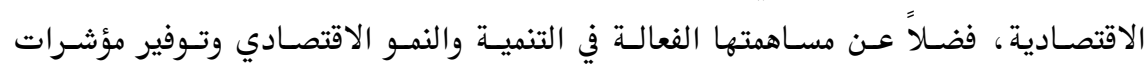

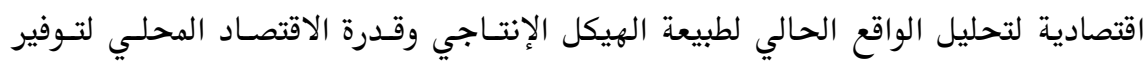

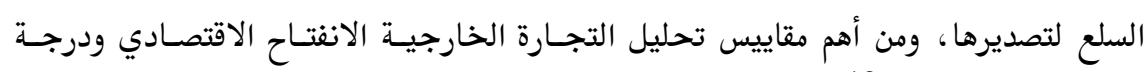

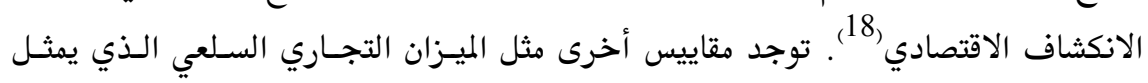

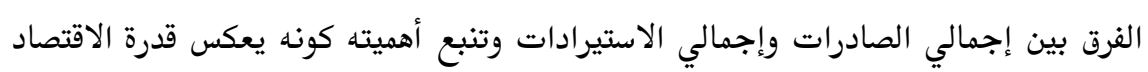

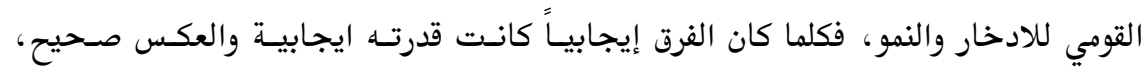

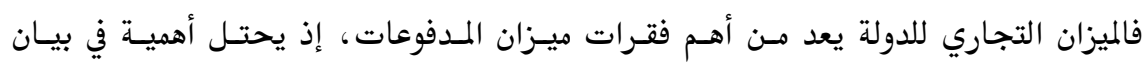

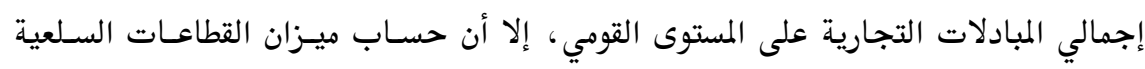

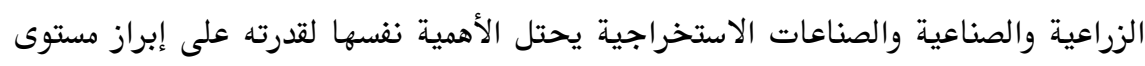

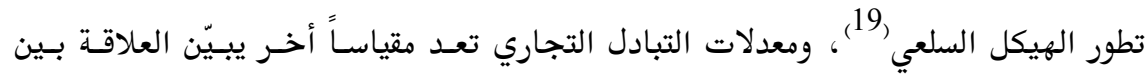
صادرات الدولة واستيراداتها ويطلق عليه معدل التبادل القيمي الذي يمثل نسبة مئوية نقدية التهدية

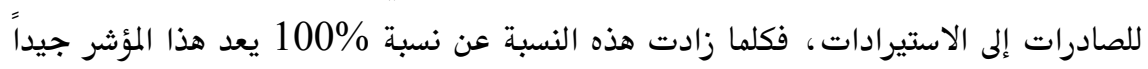

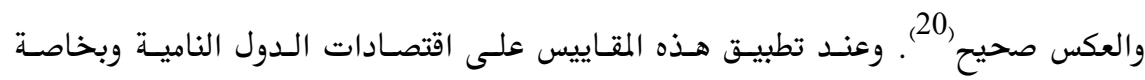


النفطية منها أو التي تصدر المواد الأولية الخام مقابل استيراد سـلع مصنعة فإنهـا لا تعطي

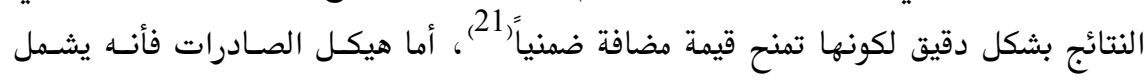

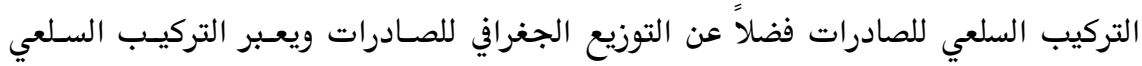

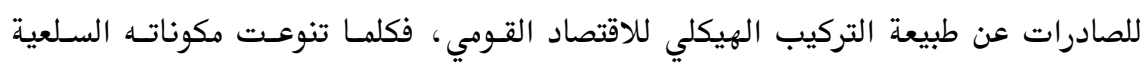

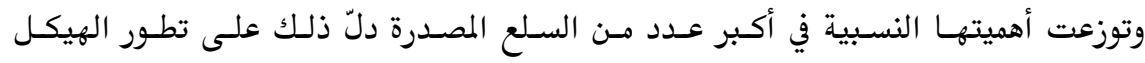

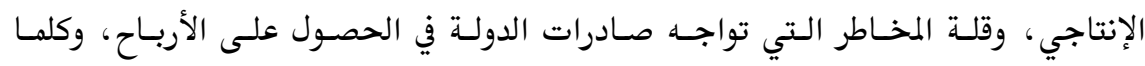

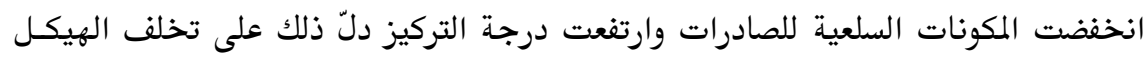

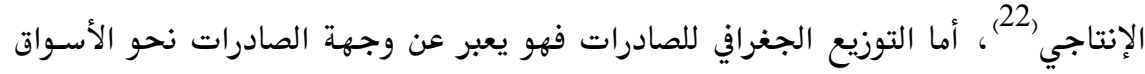

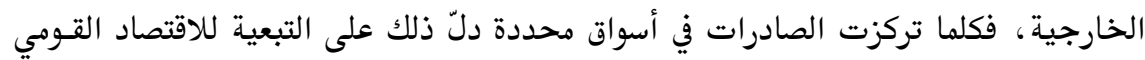

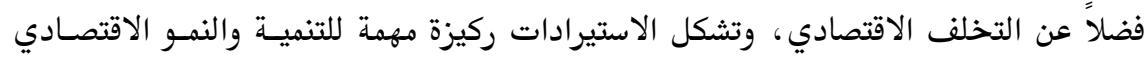

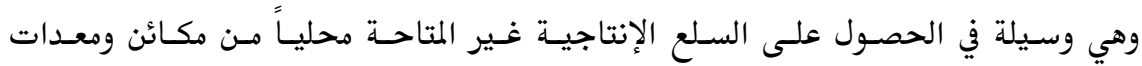

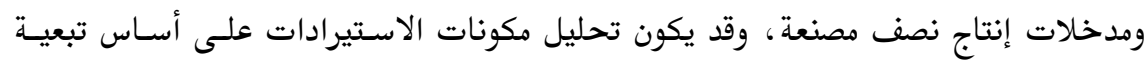

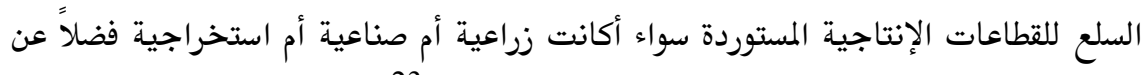
طبيعة السلع ضرورية أم كمالية أم استهلاكية أم استثمارية(23).

7- الدراسات الاقتصادية السابقة: أما الدراسات الاقتصادية السابقة التي تناولـت التجــارة

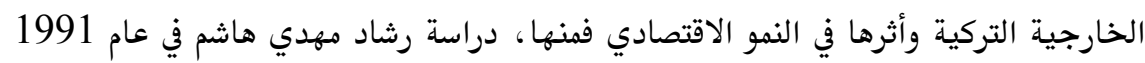

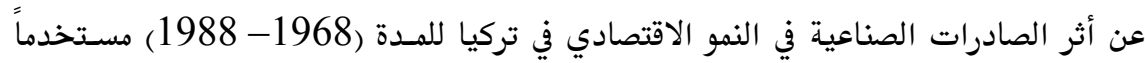

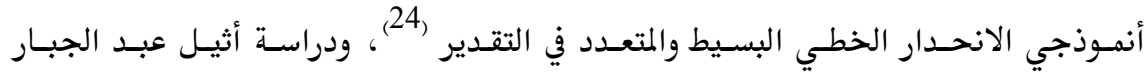

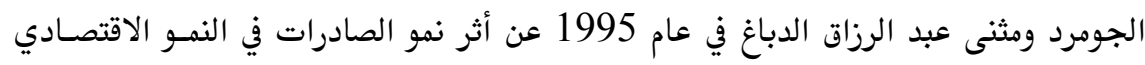

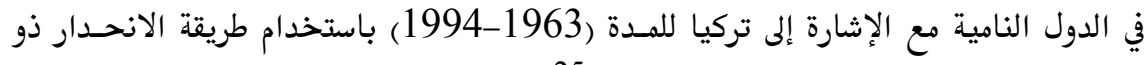
المرحلتين (Two Stages Regression) (25) ، ودراسة هاشم محمد سعيد رشيد الزيباري

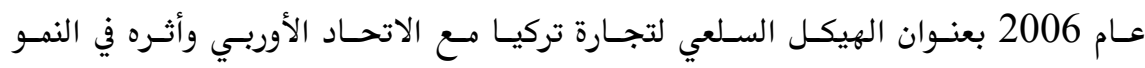

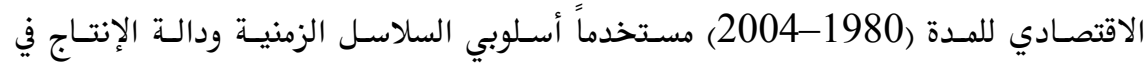
التقدير فضلاً عن استخدامه أنموذجي التقدير الخطي واللوغارتمي. 

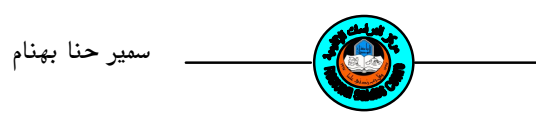

المبحث الثاني: الملامح الرئيسة للقطاعات السلعية التركية

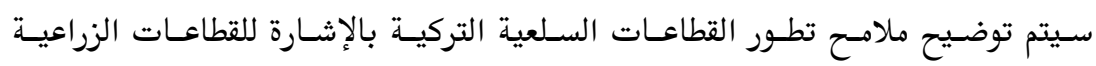

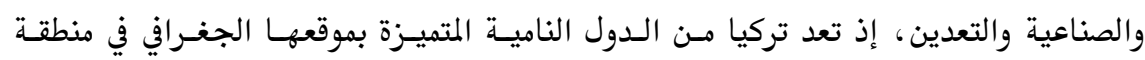

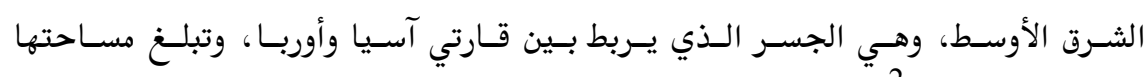

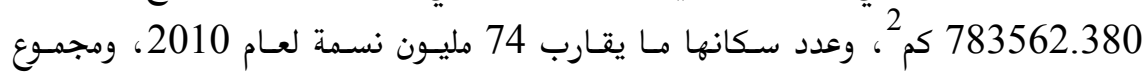

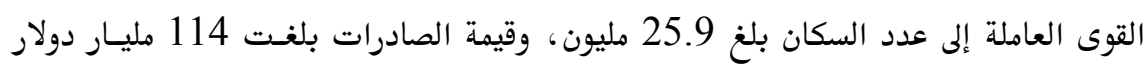

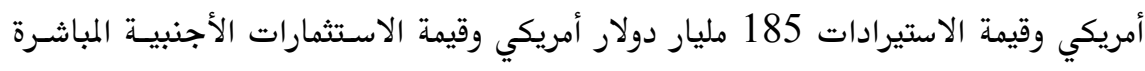

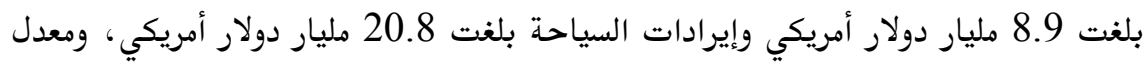

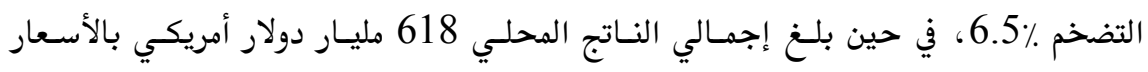

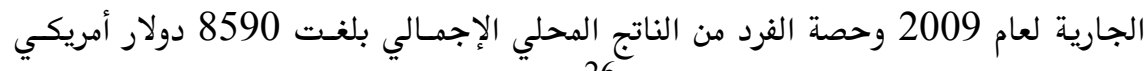

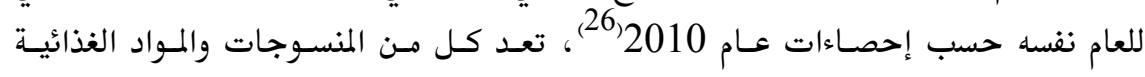

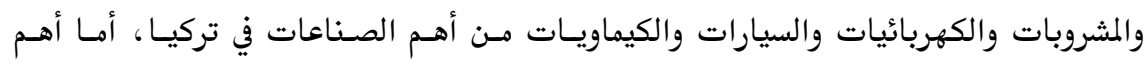

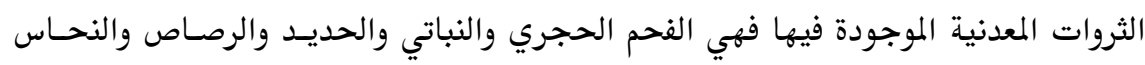

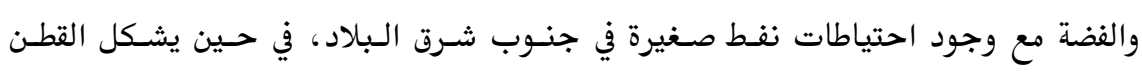

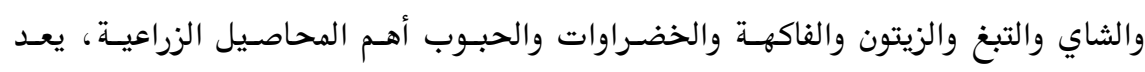

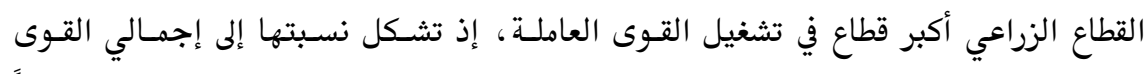

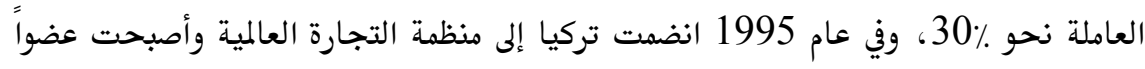

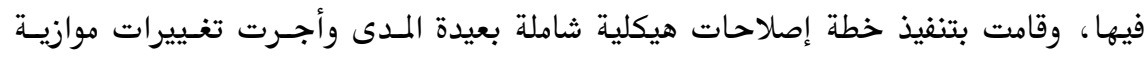

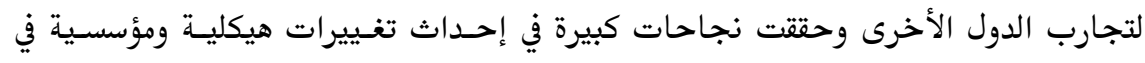

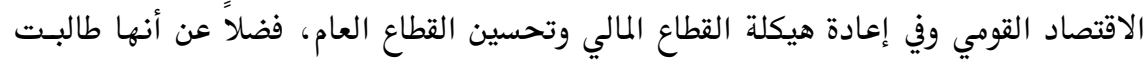

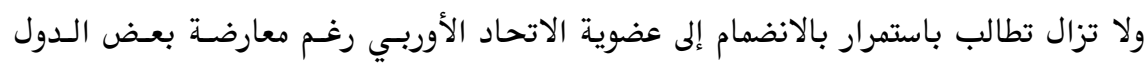

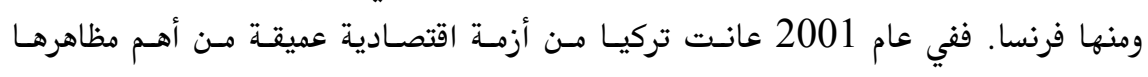

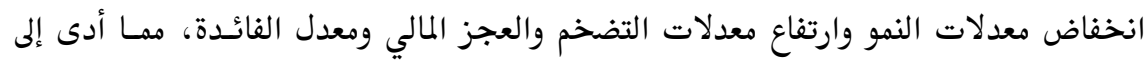

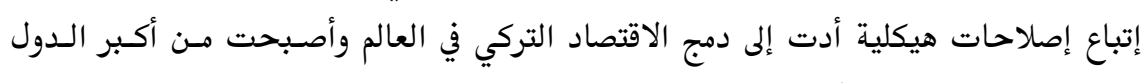

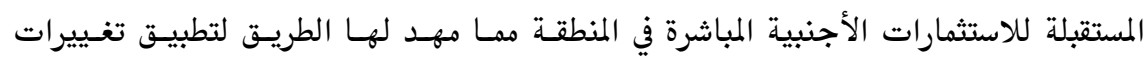




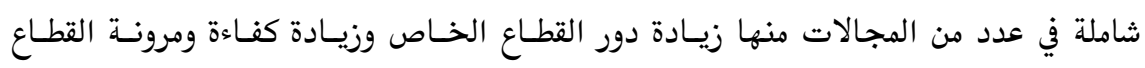

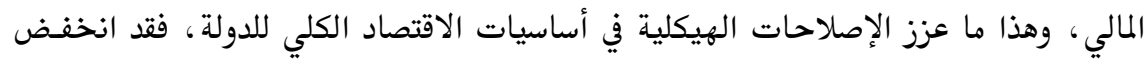

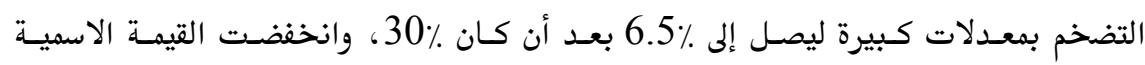

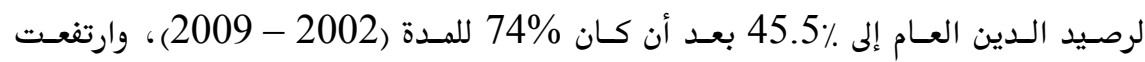

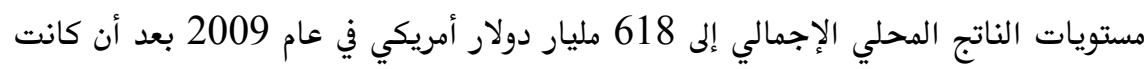

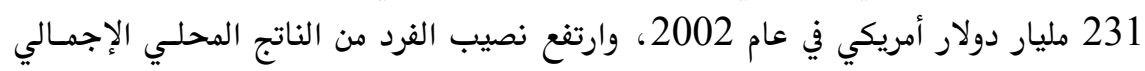

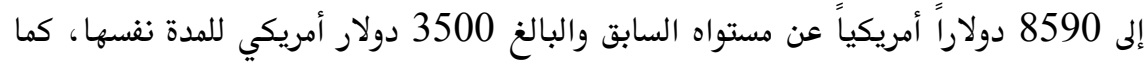

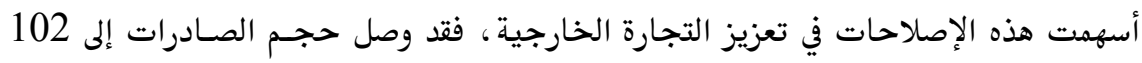

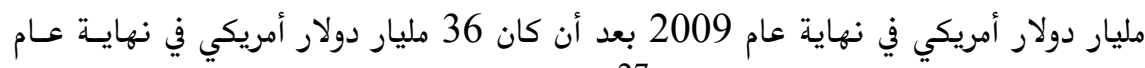

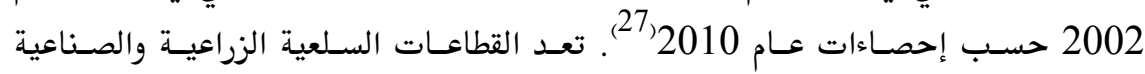

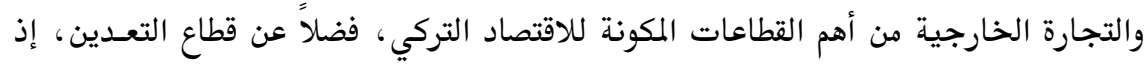

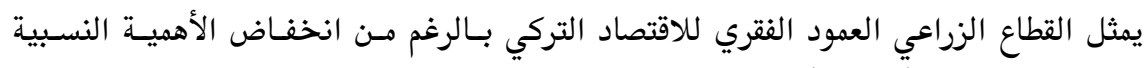

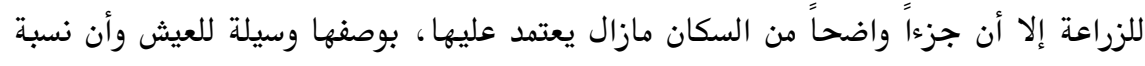

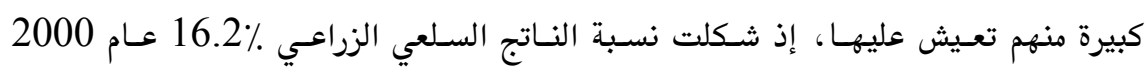

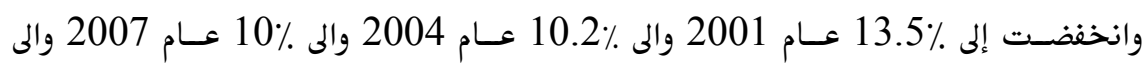

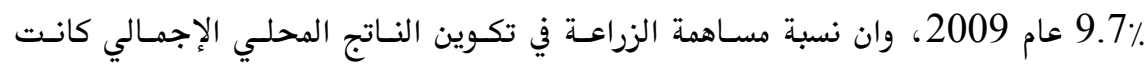

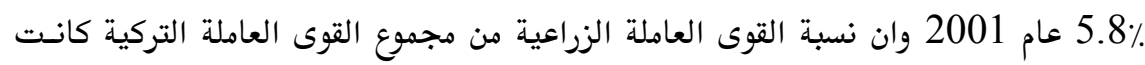

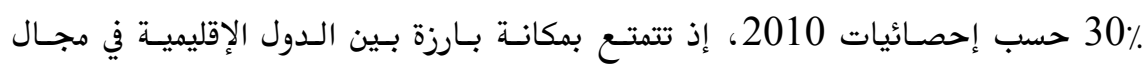

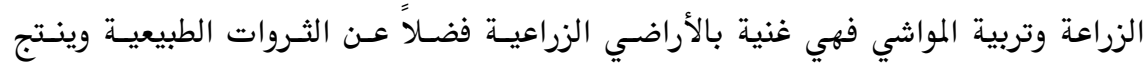

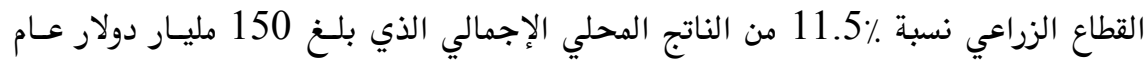

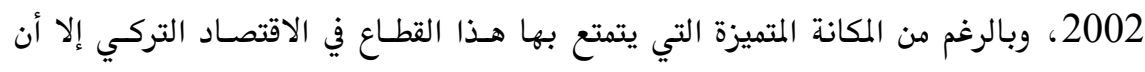

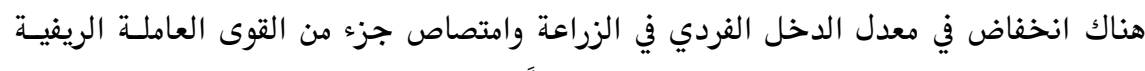

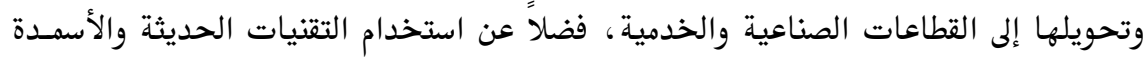

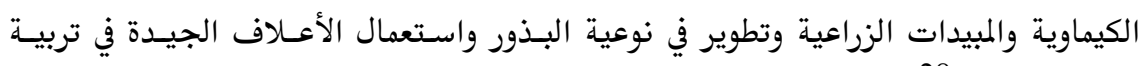

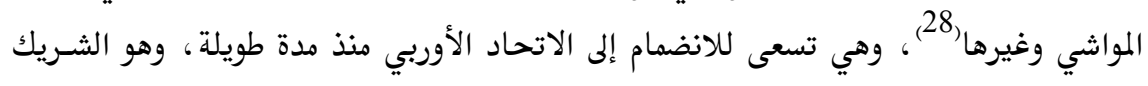

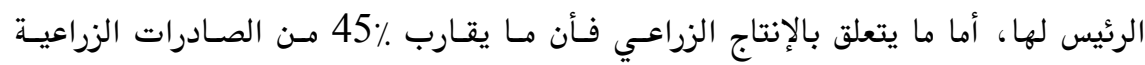



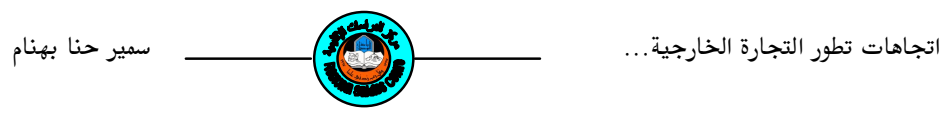

التركية و.25 من الاستيرادات هي مسن حصـة الاتحساد الأوربسي، ومنــ عـام 1995 أحتـل

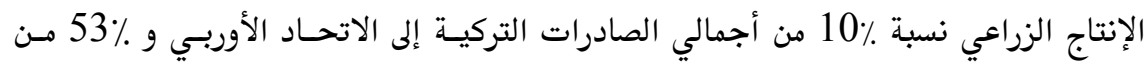

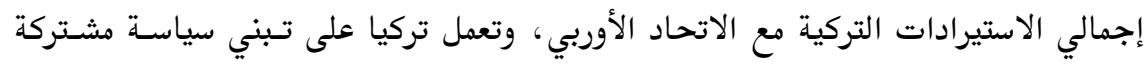

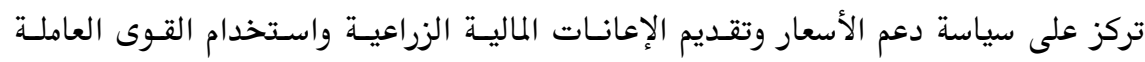

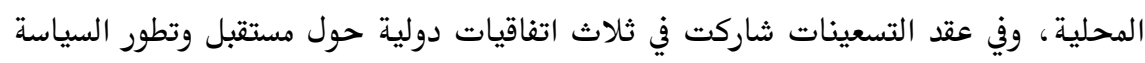

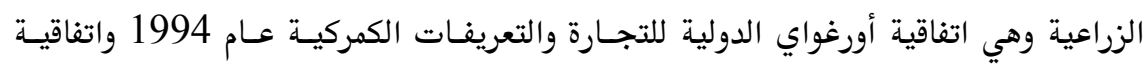

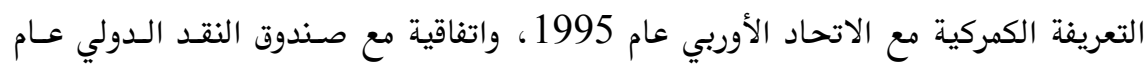

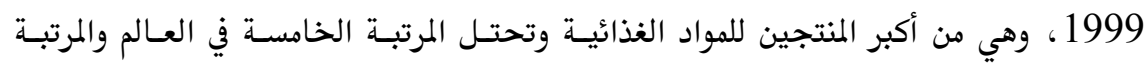

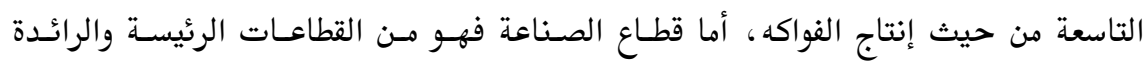

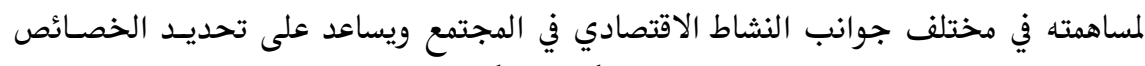

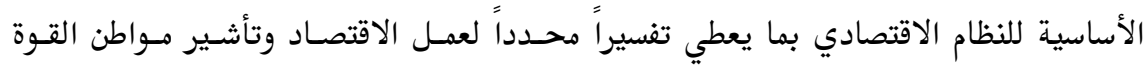

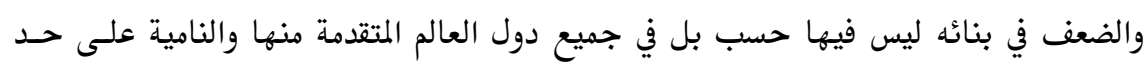

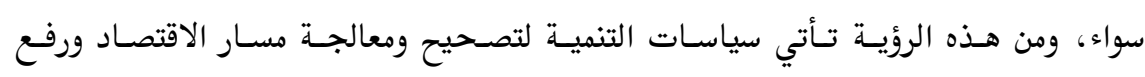

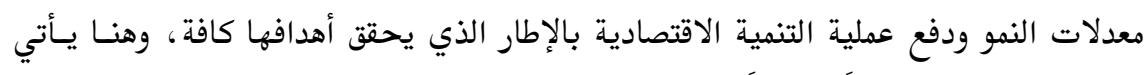

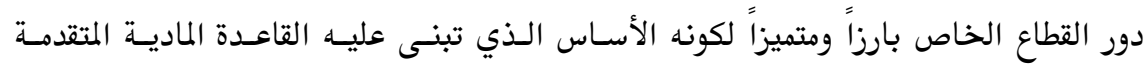

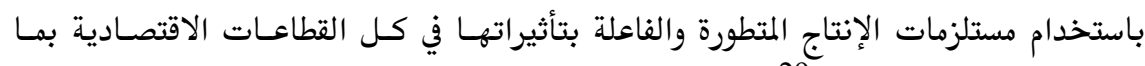

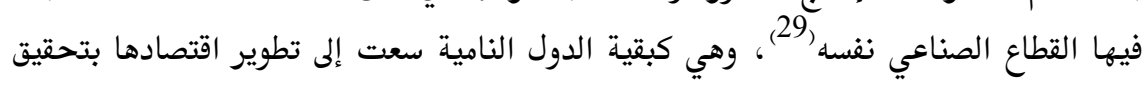

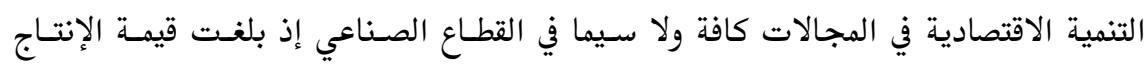

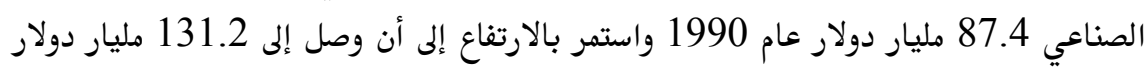

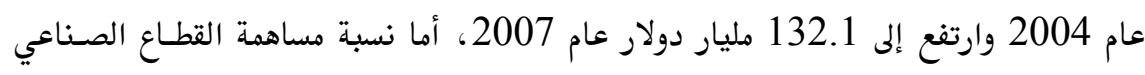

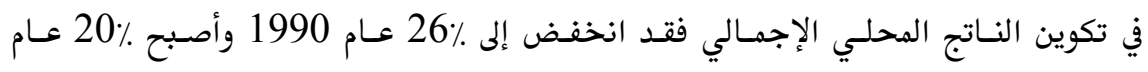

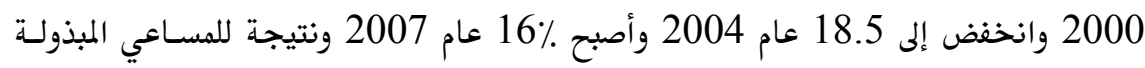

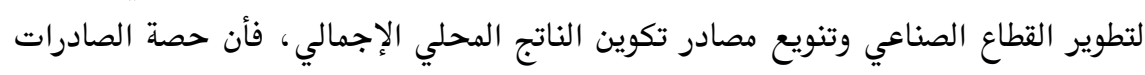
الصناعية التركية بلغت \%84.8\% في عام 2004 وارتفعت إلى ـ

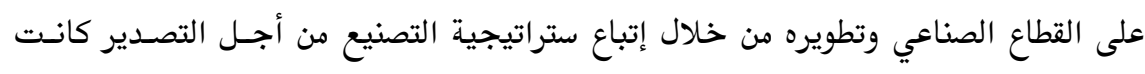

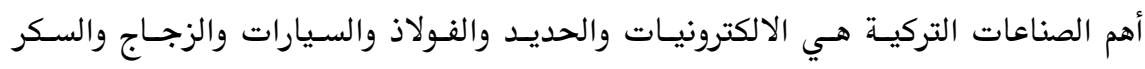


والسمنت والنسيج والأغذية، ولصـناعة السمنت دور أسـاس في الاقتصـاد التركي إذ تحتـل

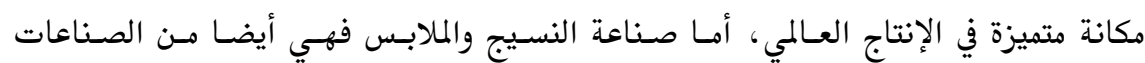

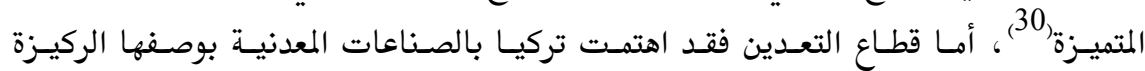

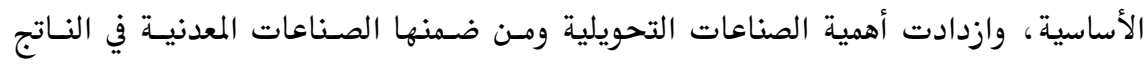

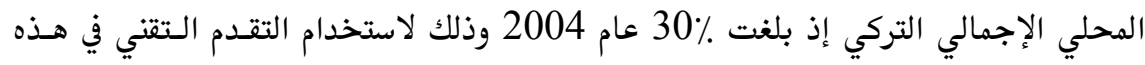

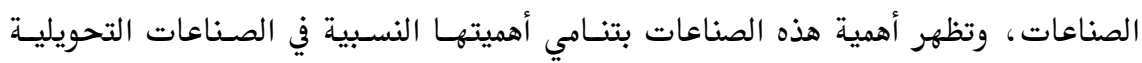

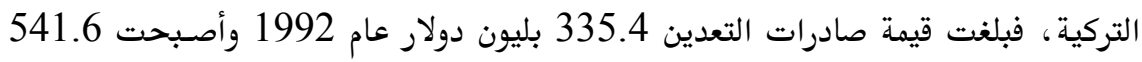

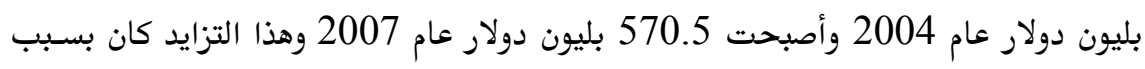
السياسات الاقتصادية التي اتبعتها تركيا في تنويع مصادر إيراداتها العامة من خلال التركيـز

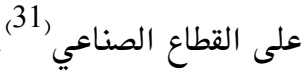

جدول (1) اتجاهات تطور التجارة الخارجية التركية للمدة (1990- 2009$)$ (بليون دولار

أمريكي)

\begin{tabular}{|c|c|c|c|c|c|c|c|c|c|}
\hline \multirow{2}{*}{ النمدلات } & \multirow{2}{*}{ إلى الاستيرادات الصادرات } & \multirow{2}{*}{ القيمة } & \multicolumn{2}{|c|}{ الميزان التجاري } & \multirow{2}{*}{ التغيير \% ن } & \multirow{2}{*}{ الاستيرادات } & \multirow{2}{*}{ التغيير \% } & \multirow{2}{*}{ الصادرات } & \multirow{2}{*}{ المؤشرات } \\
\hline & & & العجز & الفائض & & & & & \\
\hline-9.4 & 58.1 & 35.3 & -9.300 & - & 41.2 & 22.3 & 11.5 & 12.9 & 1990 \\
\hline 0.3 & 64.6 & 34.6 & -7.400 & - & 5.6 & 21.0 & 4.9 & 13.6 & 1991 \\
\hline-6.4 & 64.3 & 37.6 & -8.200 & - & 8.7 & 22.9 & 8.2 & 14.7 & 1992 \\
\hline-8.1 & 52.1 & 44.8 & 14.100 & - & 28.7 & 29.5 & 4.3 & 15.3 & 1993 \\
\hline-6.1 & 77.8 & 41.4 & -5.200 & - & 20.9 & 23.3 & 18 & 18.1 & 1994 \\
\hline-8.0 & 60.6 & 57.4 & 14.100 & - & 53.5 & 35.7 & 19.5 & 21.6 & 1995 \\
\hline-7.1 & 53.2 & 66.8 & 20.400 & - & 22.2 & 43.6 & 7.3 & 23.2 & 1996 \\
\hline-8.3 & 54.1 & 74.8 & 22.300 & - & 11.2 & 48.5 & 13.1 & 26.3 & 1997 \\
\hline
\end{tabular}




\begin{tabular}{|c|c|c|c|c|c|c|c|c|c|}
\hline \multirow{2}{*}{ النمولات } & \multirow{2}{*}{ إلى الاستيرادات الصادرات } & \multirow{2}{*}{ القيمة } & \multicolumn{2}{|c|}{ الميزان التجاري } & \multirow{2}{*}{ التغيير٪ } & \multirow{2}{*}{ الاستيرادات } & \multirow{2}{*}{ التغيير \% } & \multirow{2}{*}{ الصادرات } & \multirow{2}{*}{ الم المؤشرات } \\
\hline & & & العجز & الفائض & & & & & \\
\hline-3.9 & 58.7 & 72.9 & 18.900 & - & 5.4 & 45.9 & 2.7 & 27.0 & 1998 \\
\hline-6.4 & 65.4 & 67.2 & 14.100 & - & 11.40 & 40.7 & 1.4 & 26.6 & 1999 \\
\hline-6.1 & 51 & 82.3 & 26.700 & - & 34 & 54.5 & 4.5 & 27.8 & 2000 \\
\hline-9.4 & 75.7 & 72.7 & 10.100 & - & 240 & 41.4 & 12.8 & 31.3 & 2001 \\
\hline-7.9 & 70 & 87.6 & 15.500 & - & 24.5 & 51.5 & 15.1 & 36.1 & 2002 \\
\hline-5.9 & 68.1 & 116.6 & 22.100 & - & 34.5 & 69.4 & 31 & 47.2 & 2003 \\
\hline-4.7 & 64.8 & 153.4 & 34.600 & - & 42.1 & 97.2 & 31.8 & 56.2 & 2004 \\
\hline-9.4 & 66.1 & 171.5 & 45.900 & - & 40.8 & 108.7 & 38.0 & 62.8 & 2005 \\
\hline-8.3 & 68.5 & 176.1 & 43.500 & - & 42.3 & 109.8 & 39.6 & 66.3 & 2006 \\
\hline-8.5 & 69.8 & 180.9 & 41.500 & - & 43.6 & 111.2 & 41.2 & 69.7 & 2007 \\
\hline-8.7 & 70.9 & 185.1 & 41.500 & - & 46.1 & 113.3 & 43.9 & 71.8 & 2008 \\
\hline-9.8 & 72.6 & 191.9 & 43.300 & - & 49.9 & 117.6 & 46.1 & 74.3 & 2009 \\
\hline
\end{tabular}


دراسات إقليمية 8 (24)

مركز الدراسات الإقليمية- _ـ (-) 
جدول (2) اتجاهات تطور مكونات الهيكل السلعي للصادرات التركية للمدة (بليون دولار أمريكي) (2009-1990)

\begin{tabular}{|c|c|c|c|c|c|}
\hline الإجمالي & الأخرى السلع & الصناعية & سلع التعدين & الزراعية & المؤشرات \\
\hline 12.924 & - & 10.349 & 0.326 & 2.249 & 1990 \\
\hline 13.600 & 0.044 & 10.686 & 0.285 & 2.585 & 1991 \\
\hline 14.700 & 0.013 & 12.286 & 0.267 & 2.134 & 1992 \\
\hline 15.400 & 0.081 & 12.794 & 0.233 & 2.292 & 1993 \\
\hline 18.100 & 0.018 & 15.518 & 0.263 & 2.301 & 1994 \\
\hline 21.700 & 0.087 & 19.089 & 0.391 & 2.133 & 1995 \\
\hline 23.200 & 0.28 & 20.237 & 0.228 & 2.455 & 1996 \\
\hline
\end{tabular}




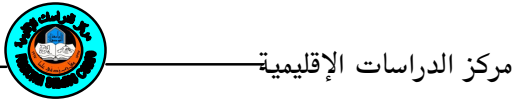

\begin{tabular}{|c|c|c|c|c|c|}
\hline الإجمالي & الأخرى السلع & الصناعية & سلع التعدين & الزراعية & السنوات المؤشرات \\
\hline 27.056 & 0.85 & 23.123 & 0.404 & 2.679 & 1997 \\
\hline 26.976 & 0.038 & 23.874 & 0.364 & 2.700 & 1998 \\
\hline 26.621 & 0.087 & 23.755 & 0.385 & 2.394 & 1999 \\
\hline 27.800 & 0.087 & 25.340 & 0.400 & 1.973 & 2000 \\
\hline 31.400 & 0.122 & 28.695 & 0.349 & 2.234 & 2001 \\
\hline 36.100 & 0.126 & 33.549 & 0.387 & 2.038 & 2002 \\
\hline 45.873 & 0.126 & 43.223 & 0.459 & 2.065 & 2003 \\
\hline 64.253 & 1.453 & 53.400 & 2.900 & 6.500 & 2004 \\
\hline 70.518 & 1.615 & 58.700 & 3.245 & 6.958 & 2005 \\
\hline 70.227 & 1.400 & 59.500 & 3.423 & 5.904 & 2006 \\
\hline 73.184 & 1.700 & 62.400 & 4.275 & 4.809 & 2007 \\
\hline 76.033 & 2.000 & 63.600 & 5.230 & 5.203 & 2008 \\
\hline 79.892 & 2.413 & 65.423 & 5.513 & 6.543 & 2009 \\
\hline
\end{tabular}

جدول (3) اتجاهات تطور مكونات الهيكل السلعي للاستيرادات التركية للمدة

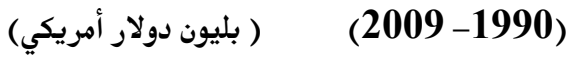

\begin{tabular}{|c|c|c|c|c|c|}
\hline الإجمالي & الأخرى السلع & الصناعية & سلع التعدين & الزراعية & المؤشرات \\
\hline 22.282 & 0.024 & 13.625 & 5.824 & 2.809 & 1990 \\
\hline 21.047 & 0.127 & 13.912 & 4.925 & 2.083 & 1991 \\
\hline 22.871 & 0.070 & 15.506 & 4.848 & 2.447 & 1992 \\
\hline 29.429 & 0.148 & 20.835 & 5.356 & 3.090 & 1993 \\
\hline 23.268 & 0.091 & 15.590 & 5.213 & 2.374 & 1994 \\
\hline
\end{tabular}




\begin{tabular}{|c|c|c|c|c|c|}
\hline الإجمالي & الأخرى السلع & الصناعية & سلع التعدين & الزراعية & المؤشرات \\
\hline 35.707 & 0.071 & 24.424 & 6.712 & 4.500 & 1995 \\
\hline 42.733 & 0.427 & 29.572 & 7.948 & 4.786 & 1996 \\
\hline 48.585 & 1.409 & 34.932 & 7.337 & 4.907 & 1997 \\
\hline 45.921 & 0.274 & 34.738 & 6.588 & 4.321 & 1998 \\
\hline 40.671 & 0.223 & 29.917 & 7.133 & 3.398 & 1999 \\
\hline 54.503 & 0.183 & 38.482 & 11.682 & 4.156 & 2000 \\
\hline 41.399 & 1.309 & 27.152 & 9.859 & 3.079 & 2001 \\
\hline 51.554 & 1.881 & 34.023 & 11.656 & 3.994 & 2002 \\
\hline 69.340 & 2.999 & 45.830 & 15.247 & 5.264 & 2003 \\
\hline 97.540 & 4.139 & 67.214 & 20.087 & 6.100 & 2004 \\
\hline 109.990 & 5.332 & 74.456 & 23.402 & 6.800 & 2005 \\
\hline 112.706 & 5.684 & 74.736 & 25.023 & 7.263 & 2006 \\
\hline 117.926 & 5.928 & 76.843 & 27.784 & 7.371 & 2007 \\
\hline 122.905 & 6.034 & 79.924 & 29.405 & 7.542 & 2008 \\
\hline 126.500 & 6.569 & 81.456 & 30.602 & 7.873 & 2009 \\
\hline
\end{tabular}

\section{المبحث الثالث: تطور التجارة الخارجية التركية والذمو الاقتصادي}

يعد قطاع التجارة الخارجية من القطاعات الأساسية في الاقتصاد التركي، لما يحققه مـن جذب للعملات الأجنبية عن طريق تصدير السلع الرأسمالية المصنعة والزراعية، وهـو مؤشـراً

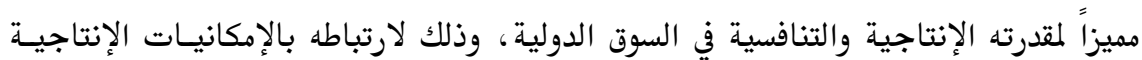
المتاحة ومدى قدرته على التصدير والاستيراد وانعكاسه على مدى توفر الأرصدة من العمـلات

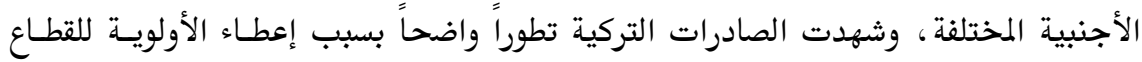
الصناعي وإتباع سياسة إحلال الاستيرادات خاصة بعد عام 1980 ، إذ ارتفعـت مـن 12.9 
بليون دولار عـام 1990 إلى 27.8 بليـون دولار عـام 2000، وإلى 70.5 بليـون دولار عـام

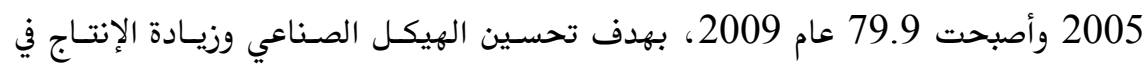
القطاعات السلعية خاصة الزراعية والصناعية، في حين شهدت استيراداتها تطوراً واضـحاً،

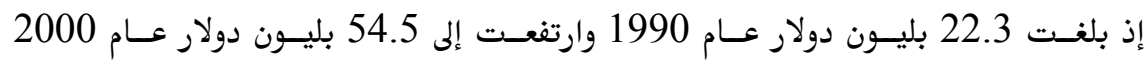

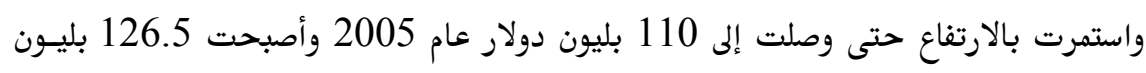

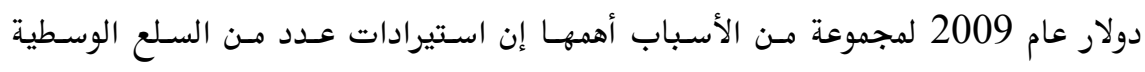

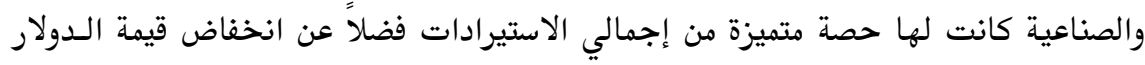

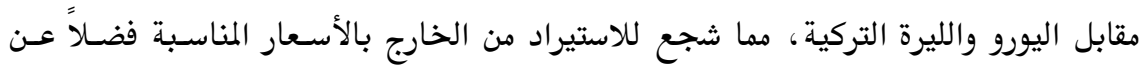

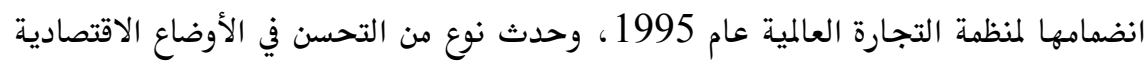
خاصة بعد عام 2000 بسبب اتفاقية الاتحـاد الكمركي مسع الاتحساد الأوربسي عـام 1996

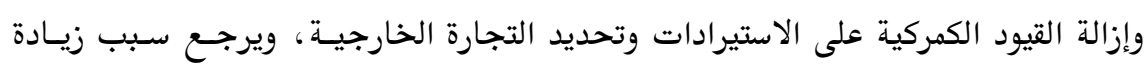

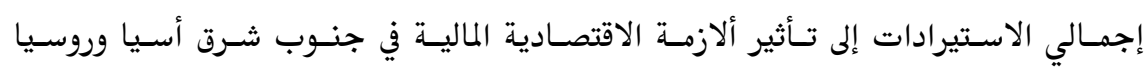

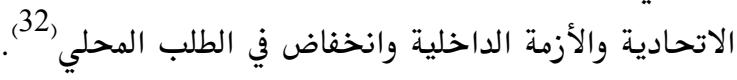

1- تطور الصادرات التركية: يعد التصدير مؤشراً لما تمتلكه الدولة من العمـلات الأجنبيـة،

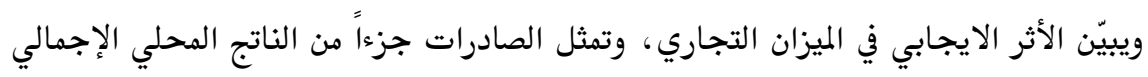

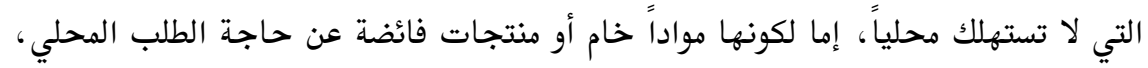

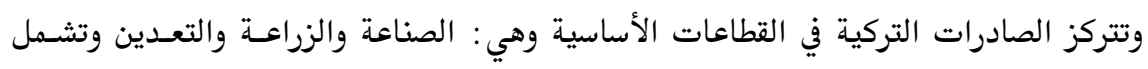

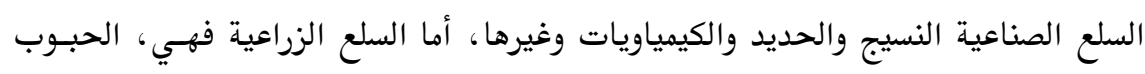

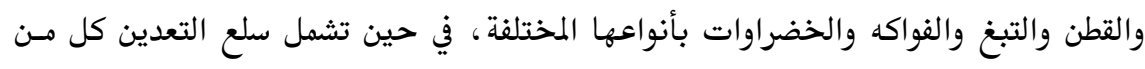

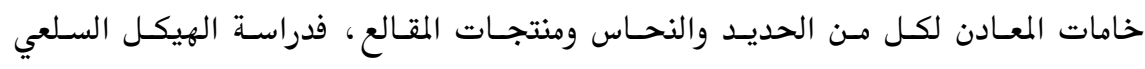

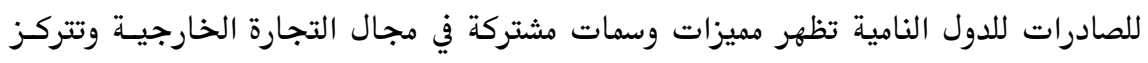
في عدد محدد من السلع المصدرة الأولية فضلاً عن التقلبـات في إيراداتهـا، مؤديـة إلى تـدهور

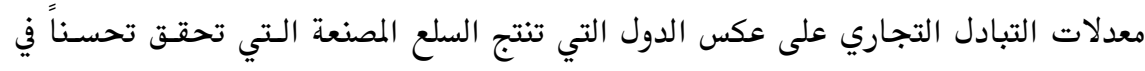

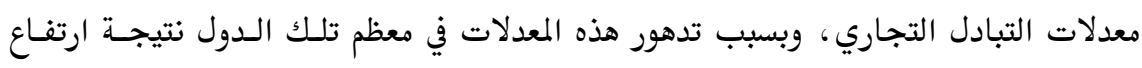


أسعار الاستيرادات أكثر منهـا للصـادرات الـتي تـؤثر سـلباً في معـدلات النهـو الاقتصـادي،

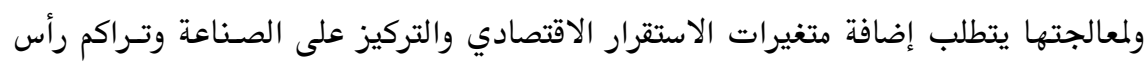

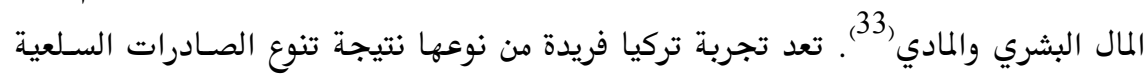

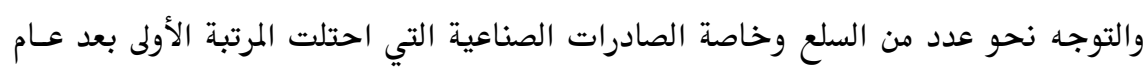

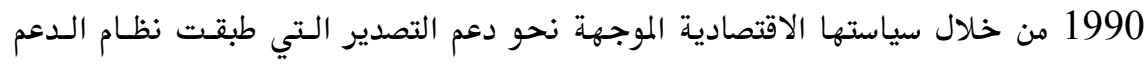

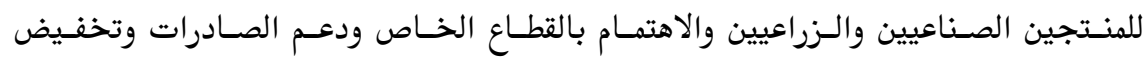

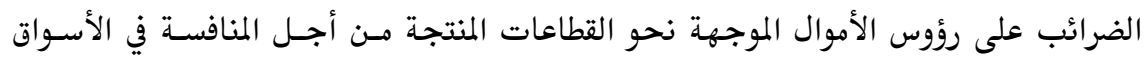

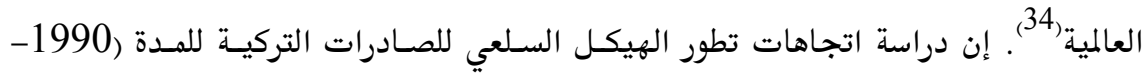

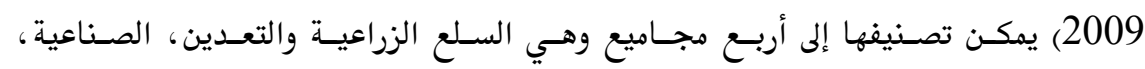

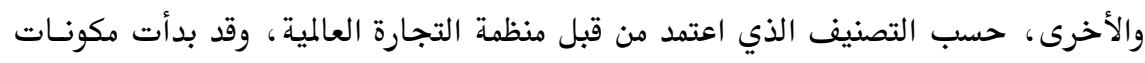

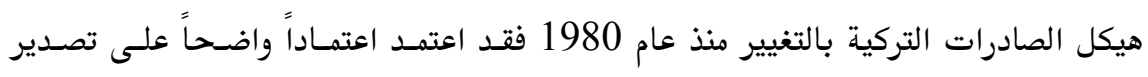

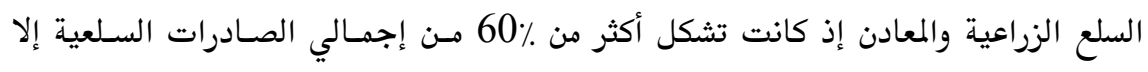

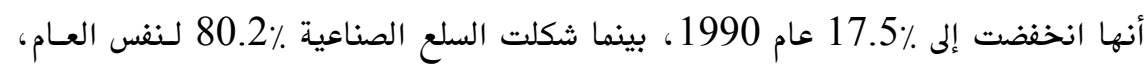
وارتفعت إلى 83.5 عام 1992 مقابل انخفاض نسبة مساهمة الصادرات من السلع الزراعيـة

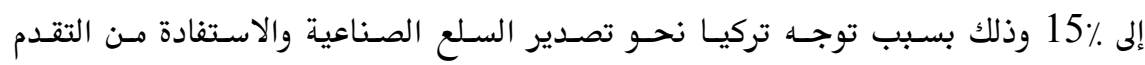

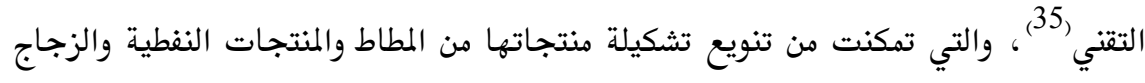

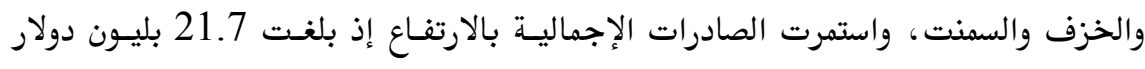

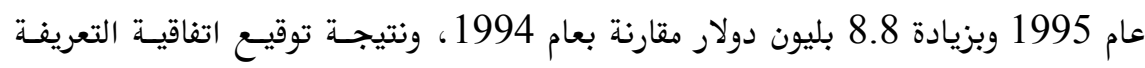

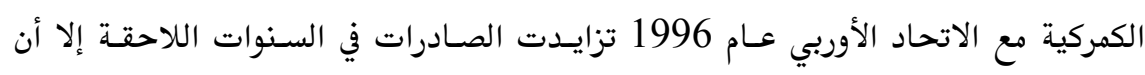

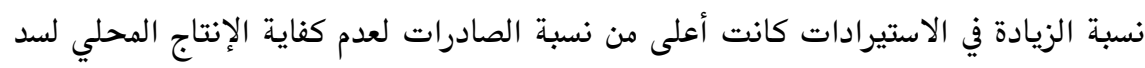

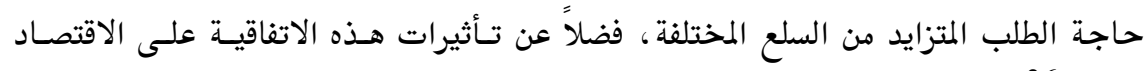
التركي (36)، وزيادة قيم الصادرات للمدة (1990 - 2000) كانت نتيجة استقرار المؤثسرات الاقتصادية خاصة بعد أزمة عام 1994 والتي كان لها تأثير واضح على عملية التنمية فضـلاً

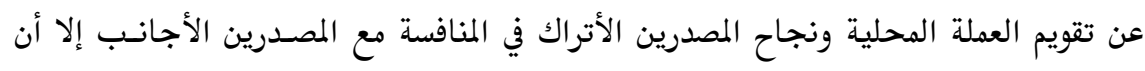

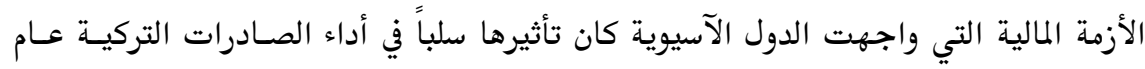


1999 وذلك بسبب كسب الصناعات درجة عالية من المنافسة ونجاحهـا في السوق العالميـة

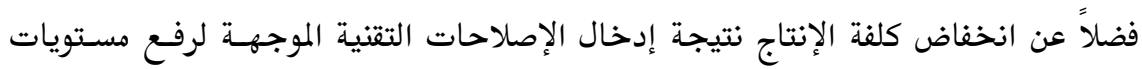

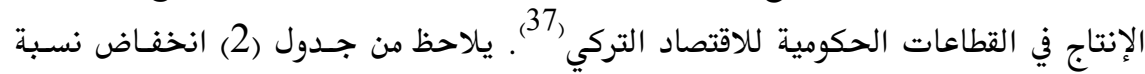

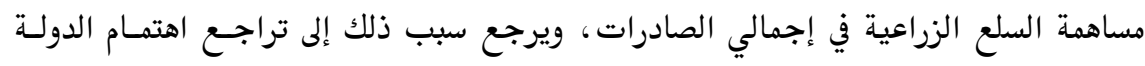

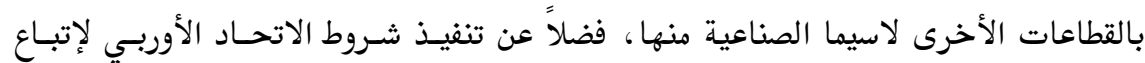

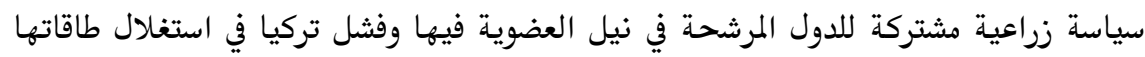

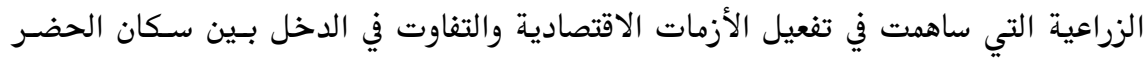

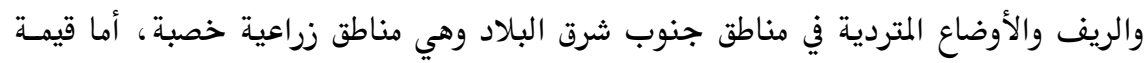

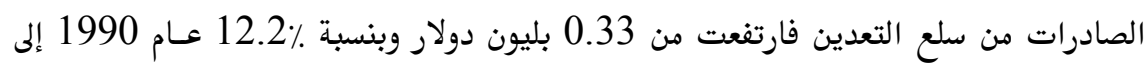

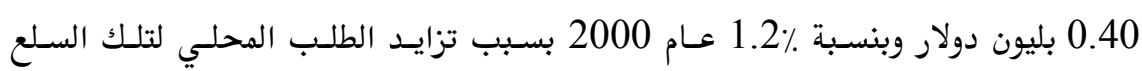
وخاصـةً في مرحلـة التصـيع فقـد كانـت بحاجــة ماسـة للصـناعة المعدنيـة لتطـوير قـدراتها

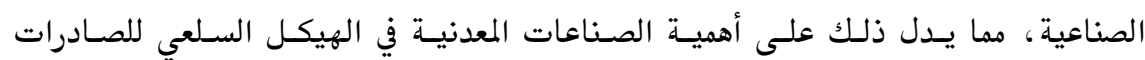

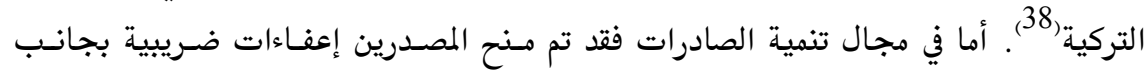

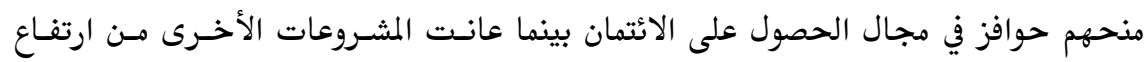
ملحوظ في تكلفة الاقتراض من الجهاز المصرفي، أما بالنسبة للمشروعات العامة المملوكة للدولة

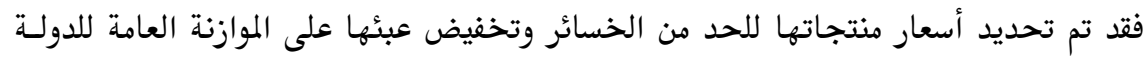

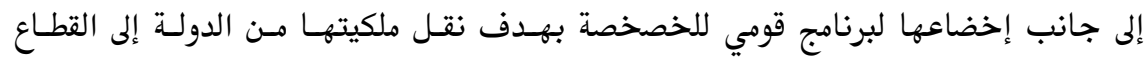

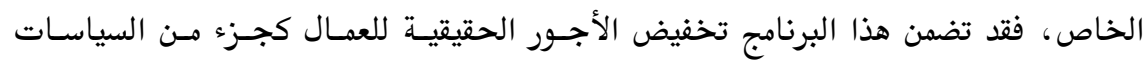

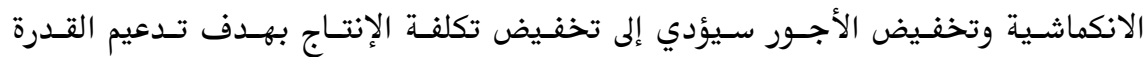

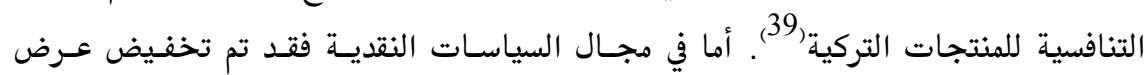

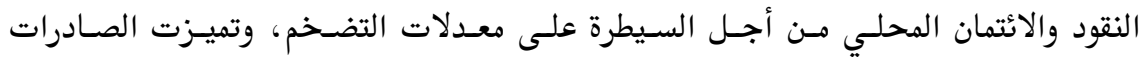

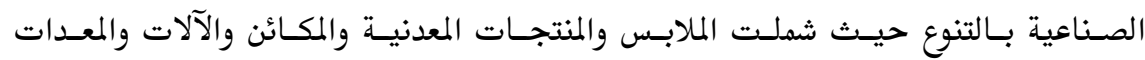
والأجهزة الكهربائية المتطورة، بجانب نجاحها في التوجه نحو أسواق جديدة خاصـة مذطقـة

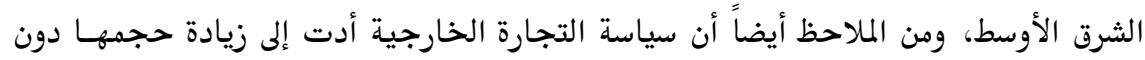

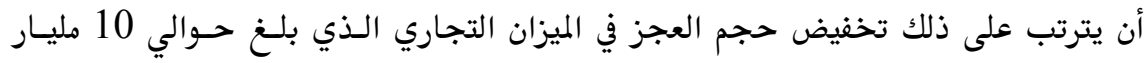



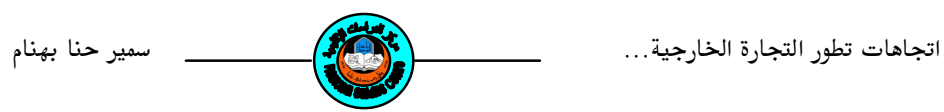

دولار في عام 1995، يرجع السبب في ذلك إلى أن الزيادة في الصادرات قد اقترنت بتصـاعد

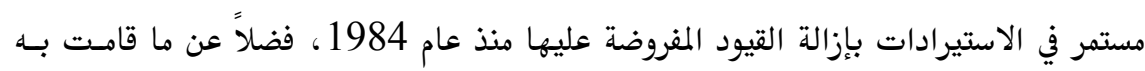

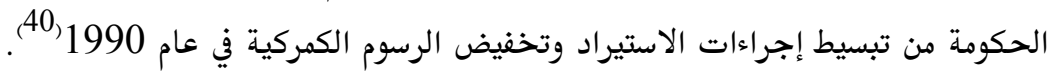

2- تطور الاستيرادات التركيـة: يمثل الهيكـل السـلعي للاستيرادات التركيـب النسبي

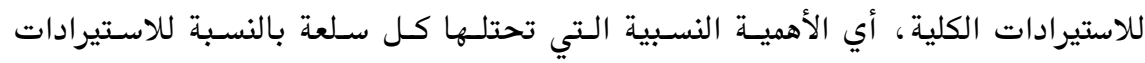

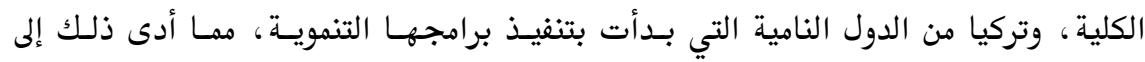

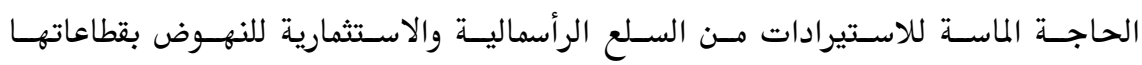

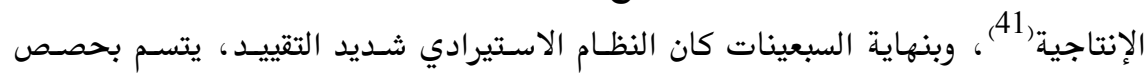

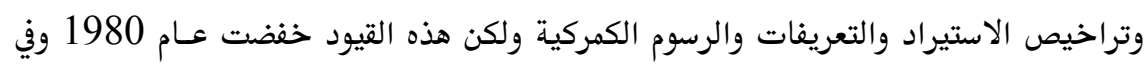

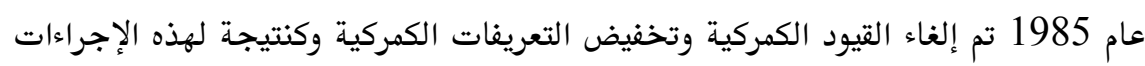
حدثت تغييرات في تركيب الهيكل السلعي للاستيرادات للمـدة (1970-

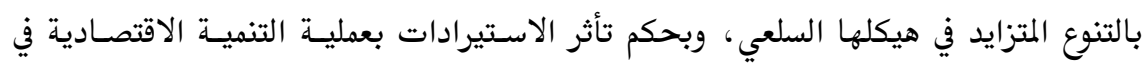

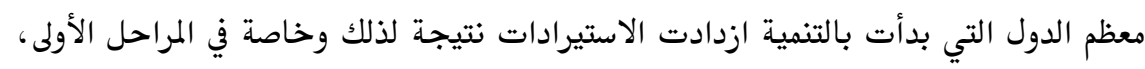

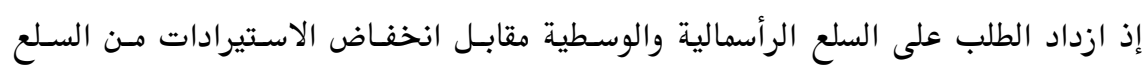
الغذائية والزراعية، وتمكنت من تطوير القطاع الصـناعي وإنتـاج السـلع الرأسماليـة والمكـائن

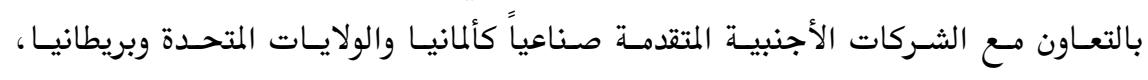

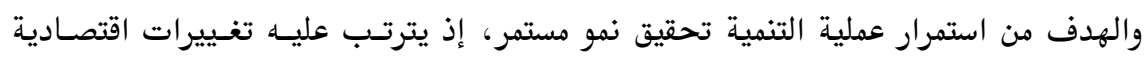

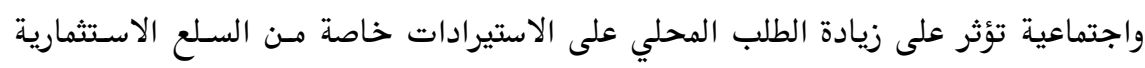

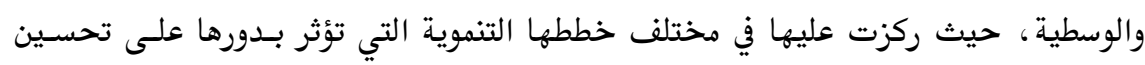

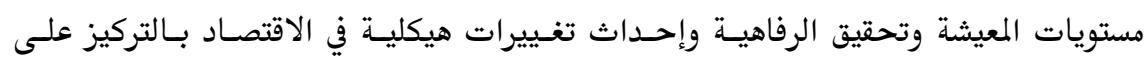

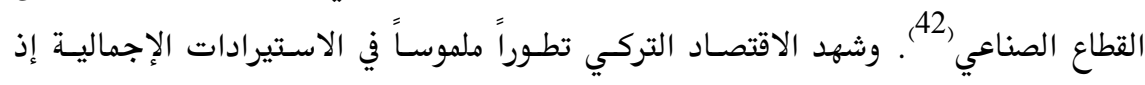

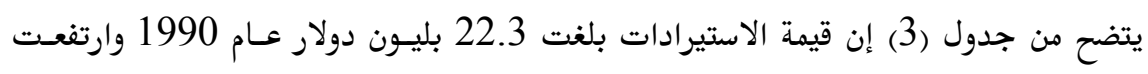

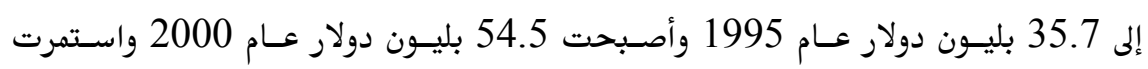
بالارتفاع حتى وصلت إلى 110 بليون دولار عام 2005 وأصبحت 195.5 بلئون دولار عام 126.5 بليون دولار عـام 
2009 مما يدل على زيادة الطلب على الاستيرادات ولاسيما السلع الرأسمالية المستخدمة في

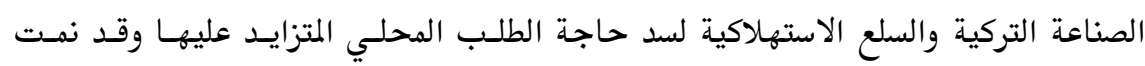

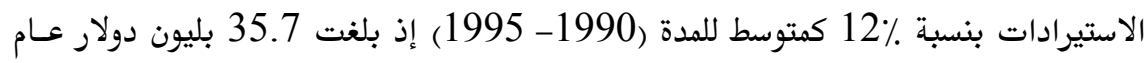

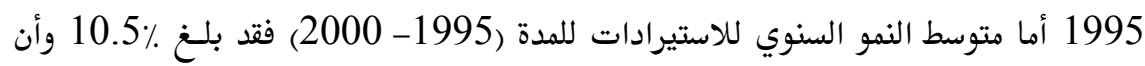

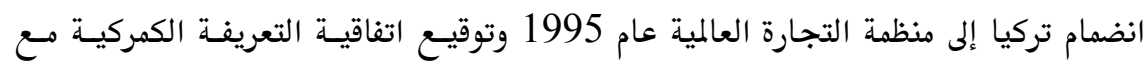

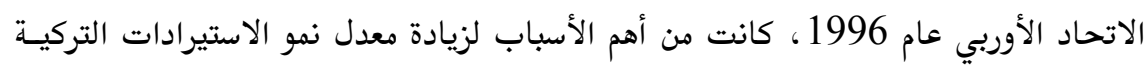

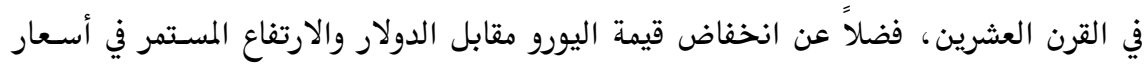

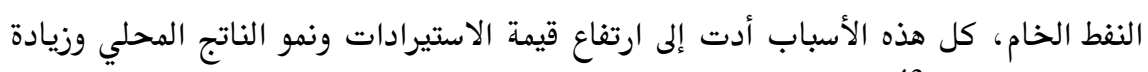

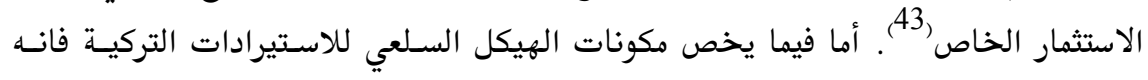

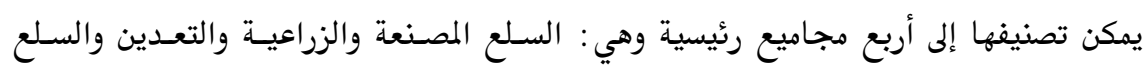
الأخرى، حسب التصنيف الدولي الذي اعتمد من قبل منظمة التجارة العالمية ووزارة التجارة

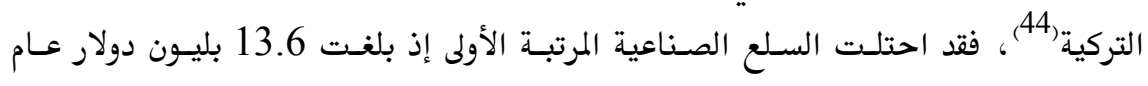

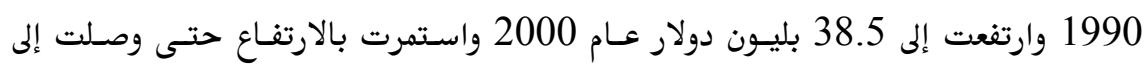

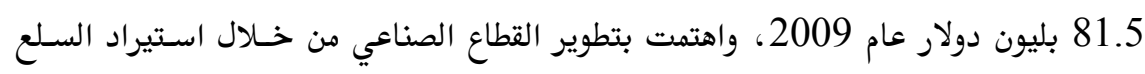

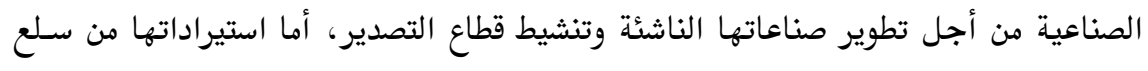

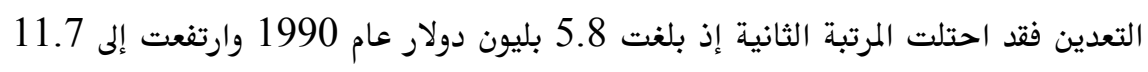

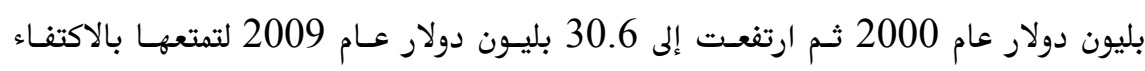

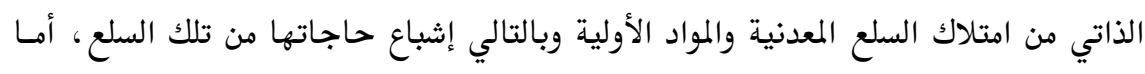

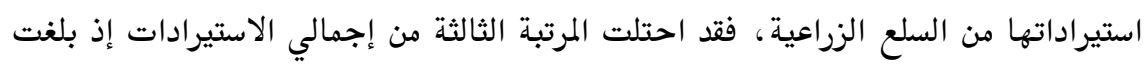

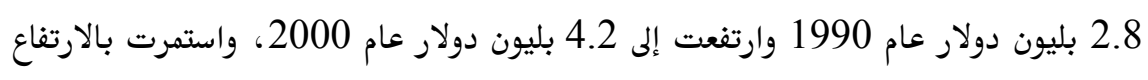

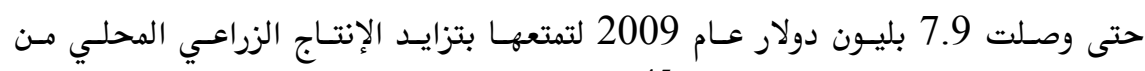

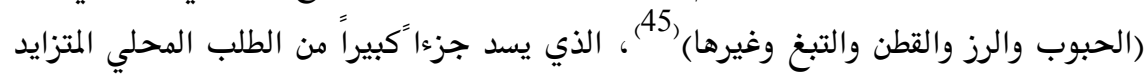

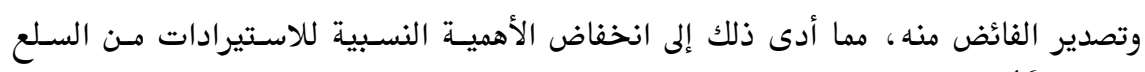
الزراعية) (46). 

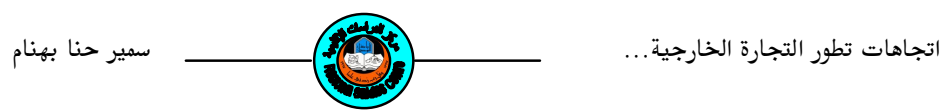

مما سبق ذكره يتضح بأن استيرادات تركيا مـن السـلع الصـناعية كانـت مرتفعـة، بينمـا

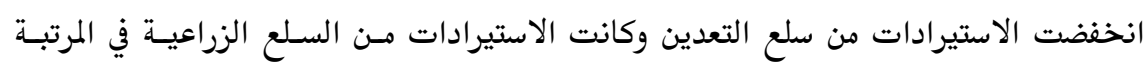

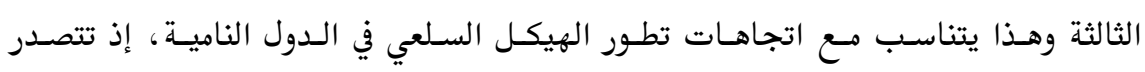

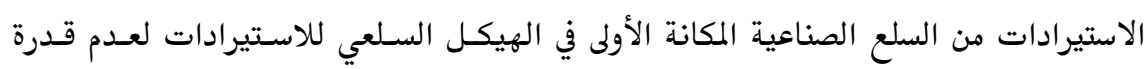

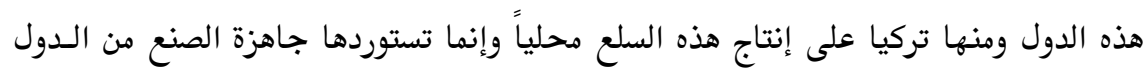

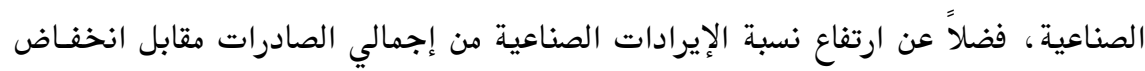

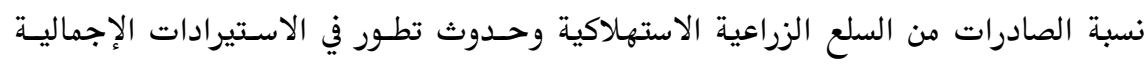

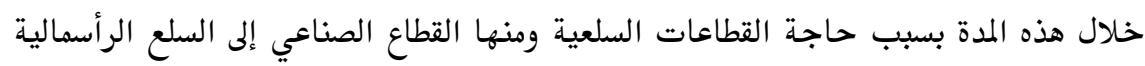

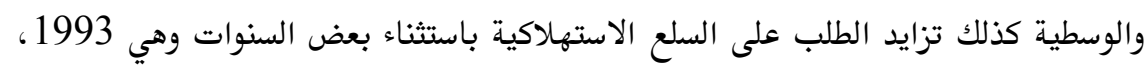

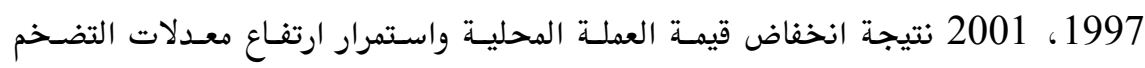

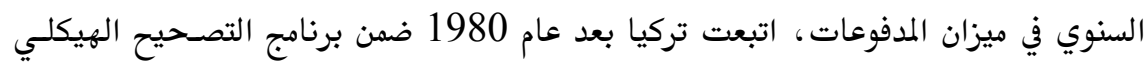

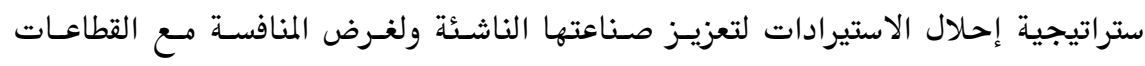
الصناعية في البلدان المتقدمة، وعززت قطاع التصدير وهيكـل الاستيرادات السـلعية باتجـاه

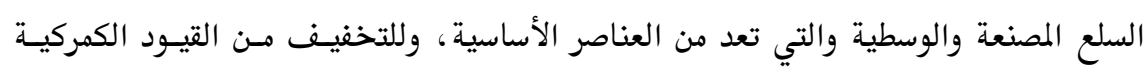
على الاستيرادات ودعم النمو وتطور الاقتصاد التركي.

3- الميزان التجـاري التركي: يتضح مـن خـلال عـرض اتجاهـات تطـور قـيم الصـادرات

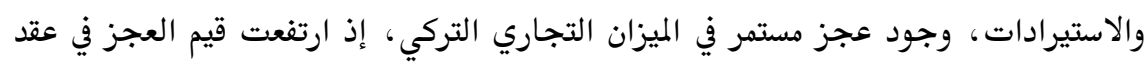

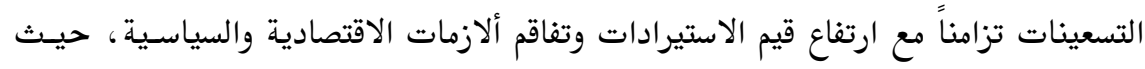

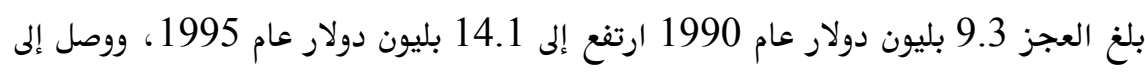

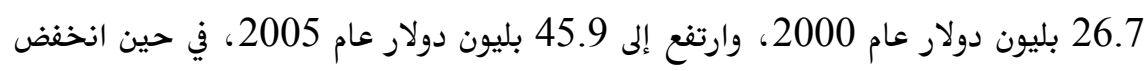

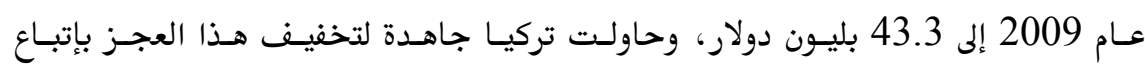

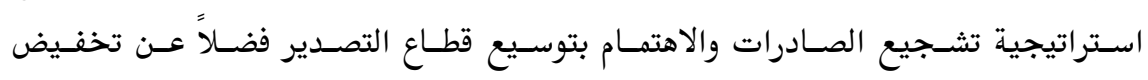

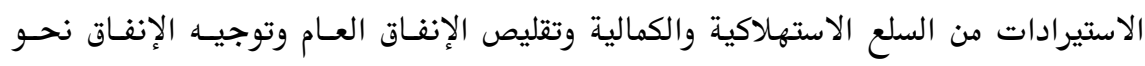

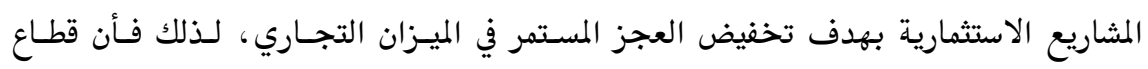


التجارة الخارجية في الدول النامية ومنها تركيا يتميز بعسد مـن الخصـائص أهمهـا : ارتفـاع

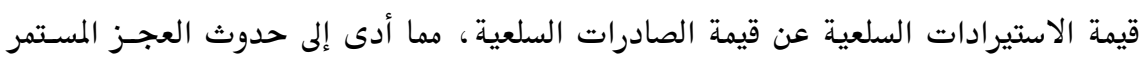
(47) في الميزان التجاري السلعي مما سبق ذكره يتضح بأن اتجاهات تطـور الصـادرات والاستيرادات التركيـة كانـت في

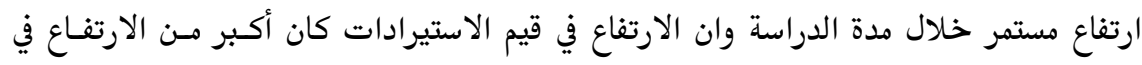

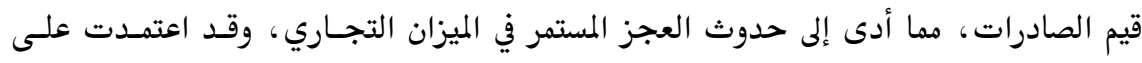

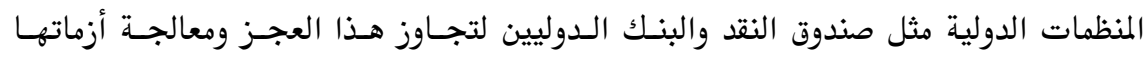
المالية والاقتصادية.

المبحث الرابع: تقدير أثر التجارة الخارجية التركية في الذمو الاقتصادي للمدة 1990 2009

سيتم توصيف الأنموذج وتحديد المـتغيرات المعتمـدة والمـتغيرات المسـتقلة وتحليـل نتـائج

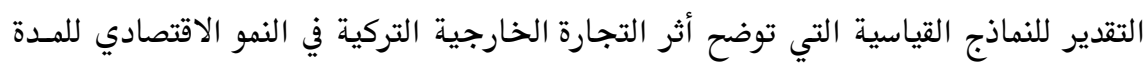

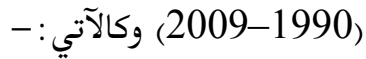

أولاً: توصـيف الأنمسوذج: يسـتخدم القيـاس الاقتصـادي بوصفه وسيلة للتأكسد مـن صـحة

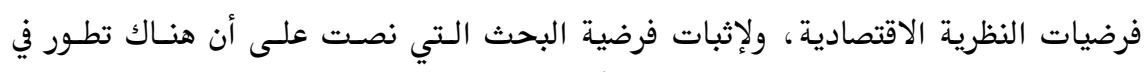

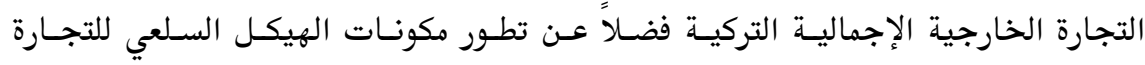

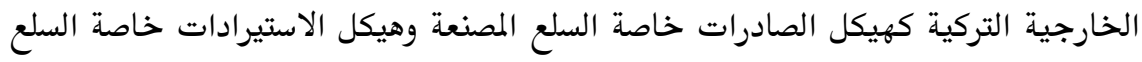

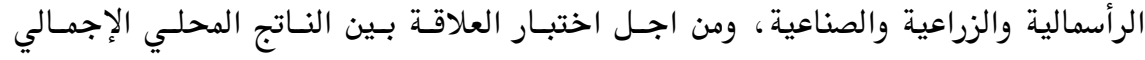

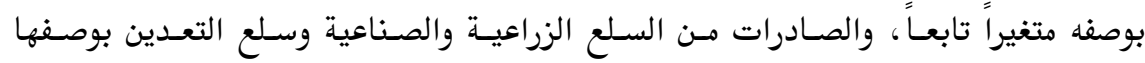
متغيرات مستقلة باستخدام أنموذج الانحدار الخطي المتعدد الذي يأخذ الصيغة الآتية : $\mathrm{GDP}=\mathrm{Bo}+\mathrm{B} 1 \mathrm{X} 1+\mathrm{B} 2 \mathrm{X} 2+\mathrm{B} 3 \mathrm{X} 3+\mathrm{Ui}$ 


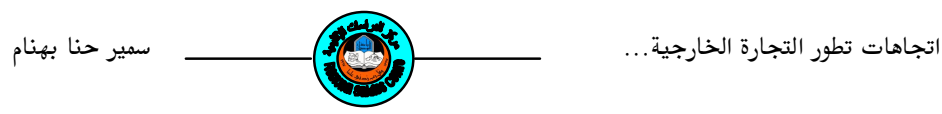

$$
\begin{aligned}
& \text { X2 } \\
& \text { X3 } \\
& \text { Ui } \\
& \text { Bo, B1, B2, B3 }
\end{aligned}
$$

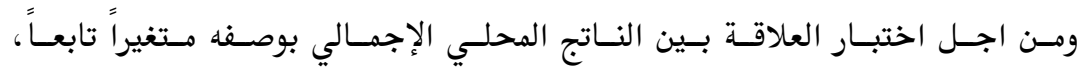

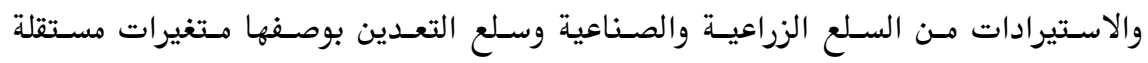

$$
\begin{aligned}
& \text { باستخدام أنموذج الانحدار الخطي المتعدد والذي يأخذ الصيغة الآتية : } \\
& \mathrm{GDP}=\mathrm{Bo}+\mathrm{B} 1 \mathrm{X} 1+\mathrm{B} 2 \mathrm{X} 2+\mathrm{B} 3 \mathrm{X} 3+\mathrm{Ui}
\end{aligned}
$$

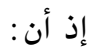

$$
\begin{aligned}
& \text { = GDP } \\
& \text { = X1 } \\
& \text { = X2 } \\
& \text { = X3 } \\
& \text { = Ui } \\
& \text { Bo, B1, B2, B3 } \\
& \text { أما في حالة الصادرات من السلع الرأسمالية والوسيطة والاستهلاكية سيأخذ الأنموذج الصيغة } \\
& \text { الآتية : } \\
& \mathrm{GDP}=\mathrm{Bo}+\mathrm{B} 1 \mathrm{X} 1+\mathrm{B} 2 \mathrm{X} 2+\mathrm{B} 3 \mathrm{X} 3+\mathrm{Ui}
\end{aligned}
$$

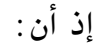

$$
\begin{aligned}
& \text { GDP } \\
& \text { = X1 } \\
& \text { X2 }
\end{aligned}
$$

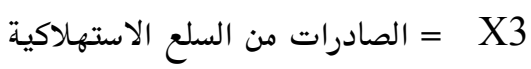

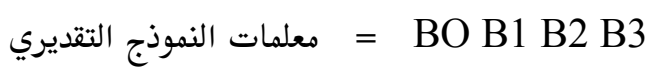


وفي حالة الاستيرادات من السلع الرأسماليـة والوسيطة والاستهلاكية سـيأخذ الأنهـوذج

الصيغة الآتية:

$\mathrm{GDP}=\mathrm{Bo}+\mathrm{B} 1 \mathrm{X} 1+\mathrm{B} 2 \mathrm{X} 2+\mathrm{B} 3 \mathrm{X} 3+\mathrm{Ui}$

إذ أن:

$$
\begin{aligned}
& \text { GDP } \\
& \text { X = X1 } \\
& \text { X = X2 } \\
& \text { X = X3 }
\end{aligned}
$$

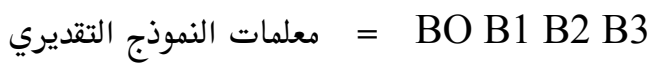

ثانيـاً: تحليسل نتــائج التقـدير لأثــر مستغيرات التجــارة الخارجيـة في النـاتج المحلـي

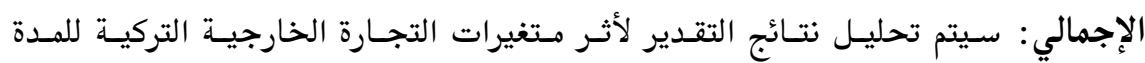

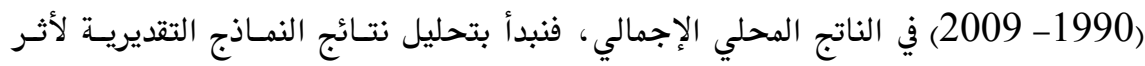

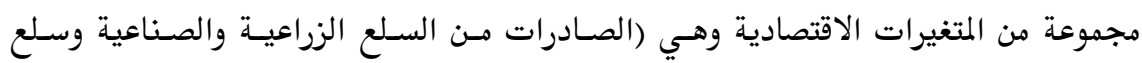

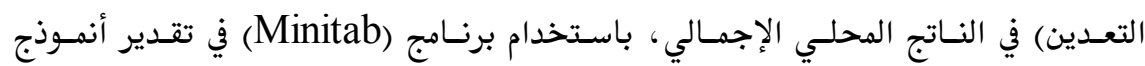

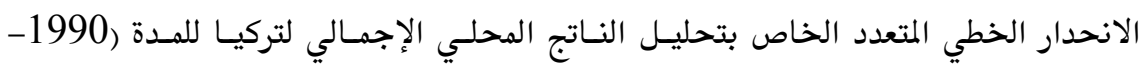

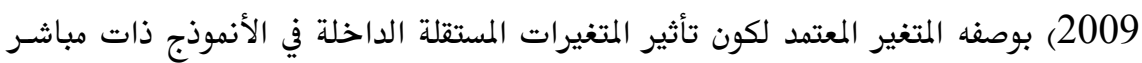

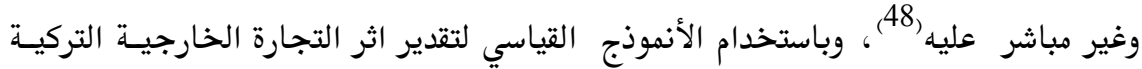
في النمو الاقتصادي(49).

جدول (4) عدد المشاهدات ودرجات الحرية وعدد المتغيرات المستقلة المعنويسة المستخدمة

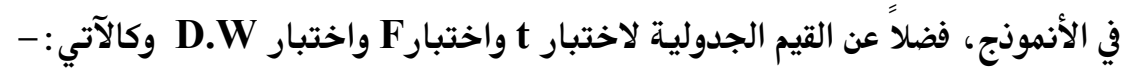



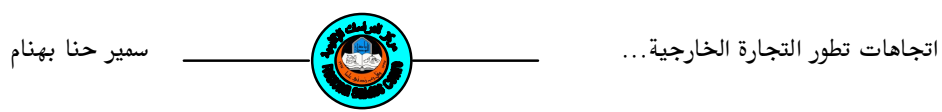

\begin{tabular}{|c|c|c|c|c|c|c|}
\hline \multirow[t]{2}{*}{ المشاهدات } & \multirow{2}{*}{ ل الحرية } & \multirow{2}{*}{ المتلغيرات } & \multirow{2}{*}{ الجديمة الاختبار t } & \multirow{2}{*}{ الاختبار Fل الجدولية } & \multicolumn{2}{|c|}{ 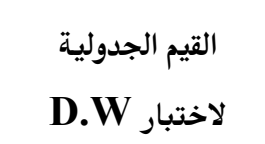 } \\
\hline & & & & & DL & DU \\
\hline 20 & 1,18 & 1 & 1.734 & 4.41 & 1.158 & 1.391 \\
\hline 20 & 1,17 & 2 & 1.740 & 3.59 & 1.015 & 1.536 \\
\hline 20 & 1,16 & 3 & 1.746 & 3.24 & 0.857 & 1.728 \\
\hline
\end{tabular}

$$
\begin{aligned}
& \text { GDP }=1.52-0.0684 \times 1+0.114 \times 2+0.0164 \times 3 \\
& T \quad=16.37-1.90 \quad 2.69 \quad 5.06 \\
& F \quad=77.03 \quad \text { R-Sq }=0.93 \quad \text { R-Sq (adj) }=0.92 \\
& \quad \text { D.W }=1.37
\end{aligned}
$$

\section{Correlations}

$\begin{array}{ccc} & \mathrm{x} 1 & \mathrm{x} 2 \\ \mathrm{x} 2 & 0.892 & \\ \mathrm{x} 3 & 0.848 & 0.900\end{array}$

يتبيّن من الأنموذج التقديري للصادرات من السلع الزراعية والصناعية وسلع التعدين بأن

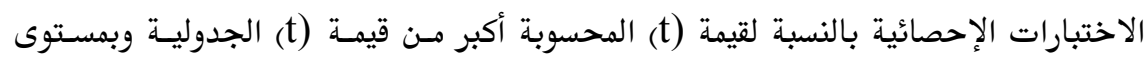

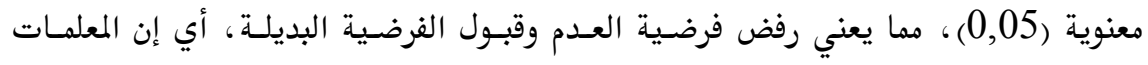

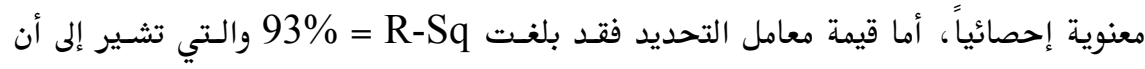

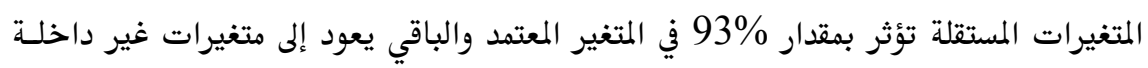

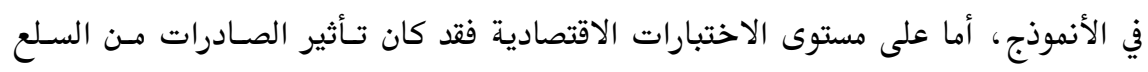

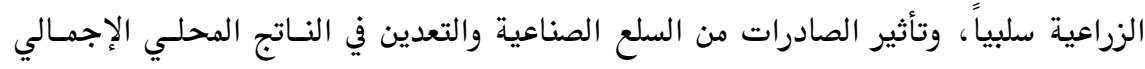

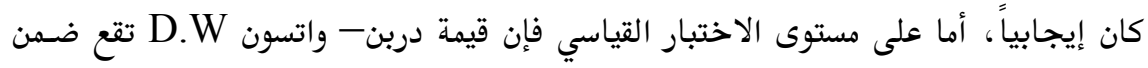


مذطقة عدم التأكد وعليه لا يمكن التأكيد أو نفي وجود مشكلة الارتباط الذاتي وذلك لوقوعهـا

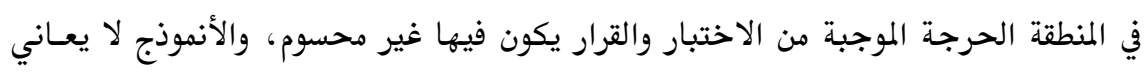

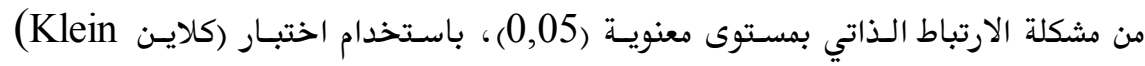

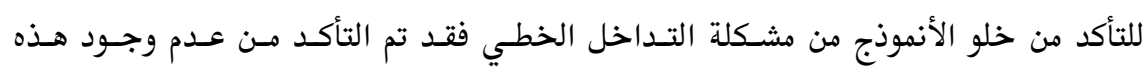

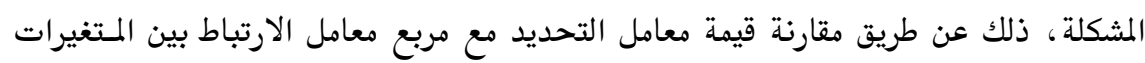

$$
\begin{array}{rlcc}
\mathrm{GDP} & =0.392 & +0.0267 \times 2 & +0.00774 \times 3 \\
\mathrm{~T} & =13.80 & 2.46 & 1.97 \\
\mathrm{~F} & =54.25 & \mathrm{R}-\mathrm{Sq}=0.87 & \mathrm{R}-\mathrm{Sq}(\mathrm{adj})=0.85 \\
& \mathrm{D} . \mathrm{W}=1.19
\end{array}
$$

\section{Correlations}

\section{$\begin{array}{cc}\mathrm{X} 2 \\ \mathrm{X} 3 & 0.909\end{array}$}

يتبيّن من الأنمـوذج التقديري للاسـتيرادات مـن السـلع الصـناعية وسـلع التعـدين بـأن

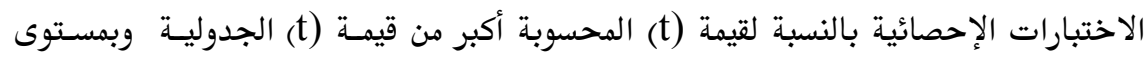

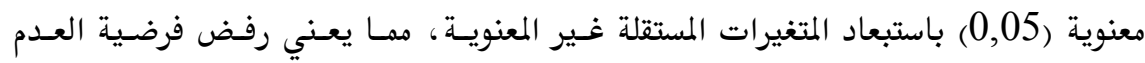

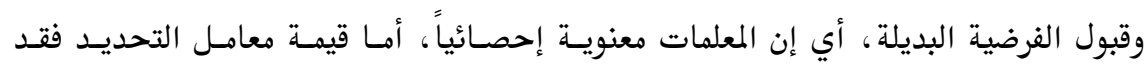

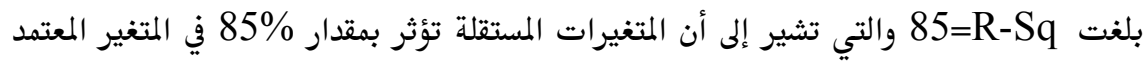

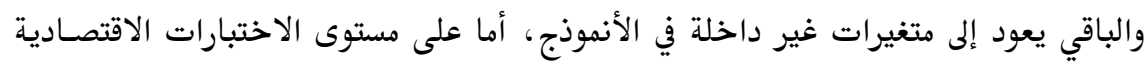

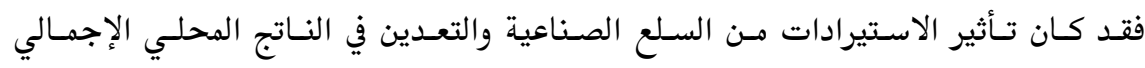

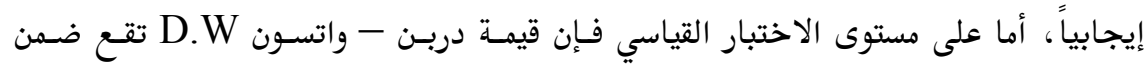

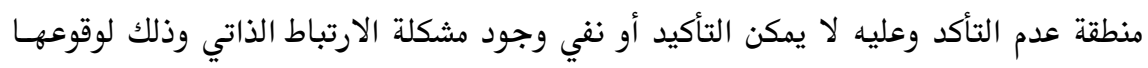

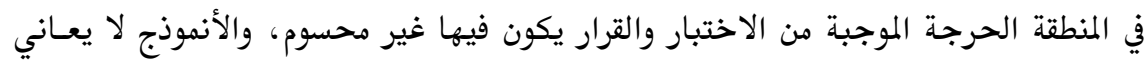

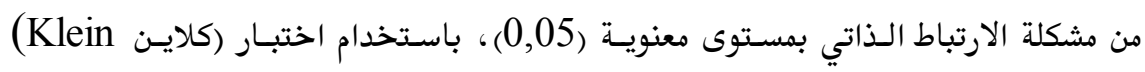

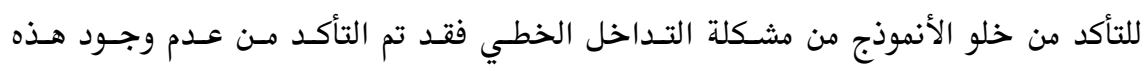




$$
\text { سمير حنا بهنام }
$$

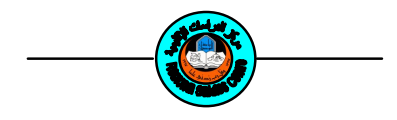

اتجاهات تطور التجارة الخارجية...

المشكلة، ذلك عن طريق مقارنة قيمة معامل التحديد مع مربع معامل الارتباط بين المتغيرات

$$
\begin{aligned}
& \mathrm{GDP}=0.237+0.0901 \times 1+0.132 \times 2 \\
& \mathrm{~T}=1.83 \quad 2.60 \quad 2.32 \\
& \mathrm{~F}=187.89 \quad \mathrm{R}-\mathrm{Sq}=0.95 \quad \mathrm{R}-\mathrm{Sq}(\mathrm{adj})=0.95 \\
& \quad \text { D. } \mathrm{W}=1.60
\end{aligned}
$$

\section{Correlations}

$\begin{array}{cc} & \mathrm{X} 1 \\ \mathrm{X} 2 & 0.968\end{array}$

يتبيّن من الأنموذج التقديري للصادرات من السلع الرأسمالية والوسيطة بـأن الاختبـارات

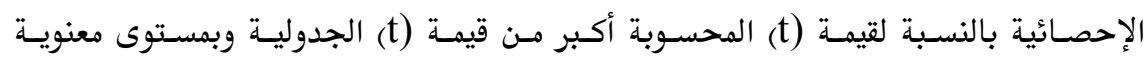

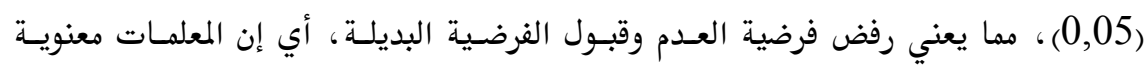

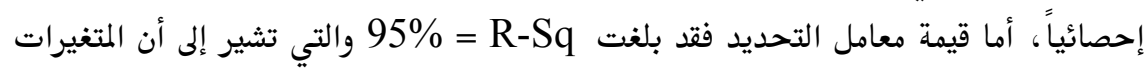

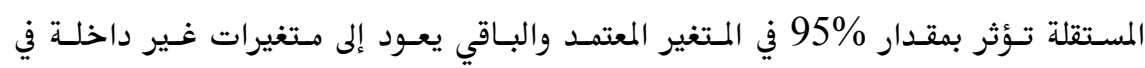

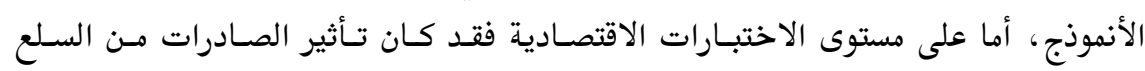

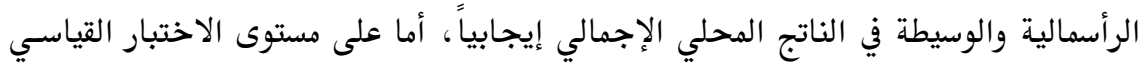

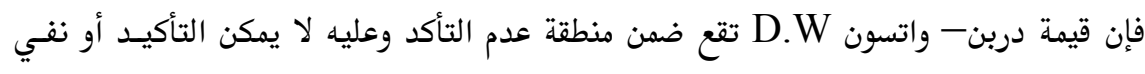

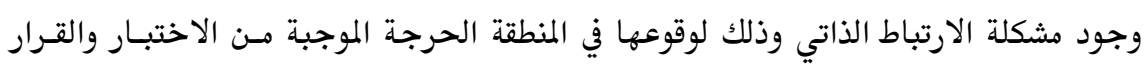

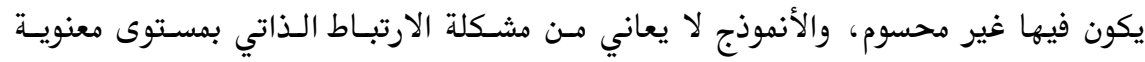

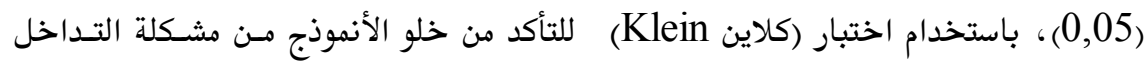

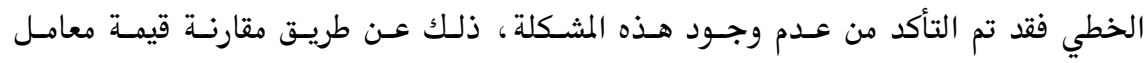
$\mathrm{GDP}=0.467+0.0410 \times 1$ التحديد مع مربع معامل الارتباط بين المتغيرات المستقلة.

$\mathrm{T}=9.17 \quad 4.43$

$\mathrm{F} \quad=19.66 \quad \mathrm{R}-\mathrm{Sq}=0.52 \quad \mathrm{R}-\mathrm{Sq}(\operatorname{adj})=0.50$

D.W $=1.20$

يتبيّن من الأنموذج التقديري للاستيرادات من السلع الرأسمالية بأن الاختبارات الإحصائية

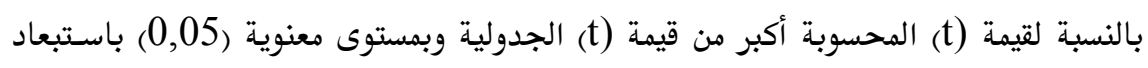


المتغيرات المستقلة غير المعنوية، مما يعني رفض فرضية العدم وقبول الفرضية البديلة ، أي إن

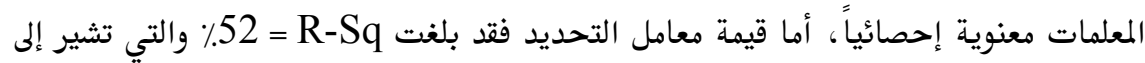

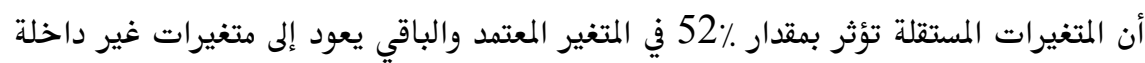

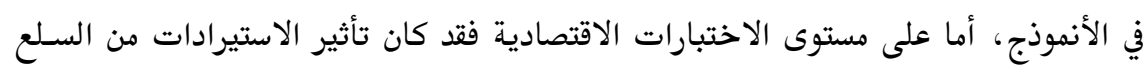

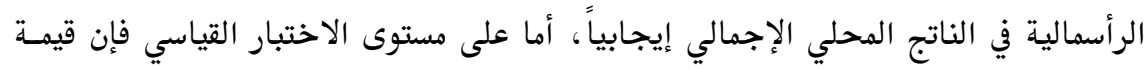

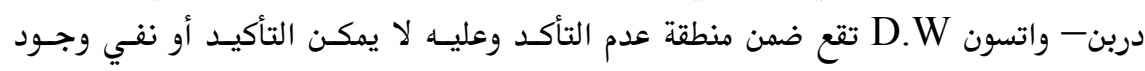

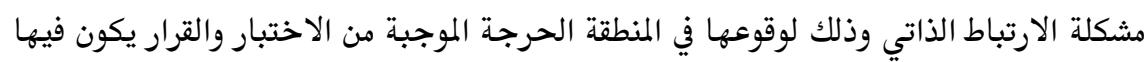

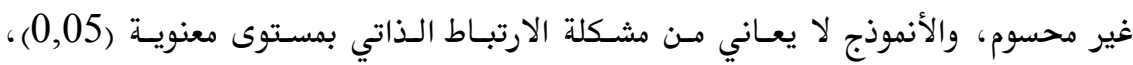

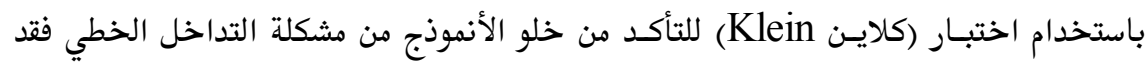

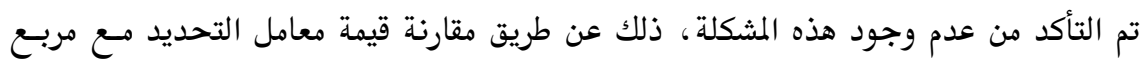
معامل الارتباط بين المتغيرات المستقلة. النتائج والمقترحات الاتباط ين المتئ

توصل الباحث إلى مجموعة من النتائج والمقترحات أهمها :- أنتانج أولاً: النتائج

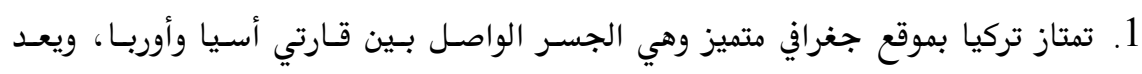

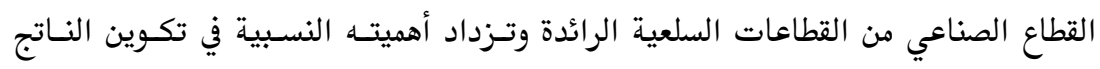

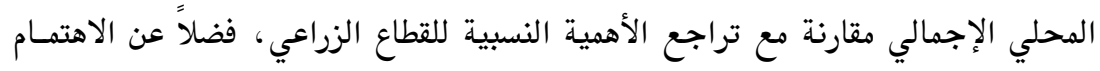
بقطاع التعدين والصناعات المعدنية كونها تسهم في النمو والتنمية الاقتصادية.

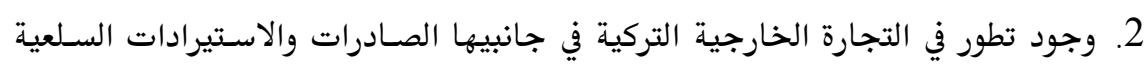

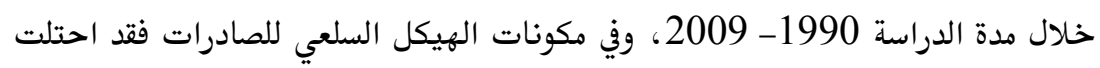

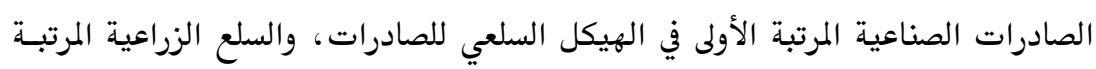
الثانية ثم تعقبها سلع التعدين والسلع الأخرى في المرتبتين الثالثة والرابعة على الترتيب.

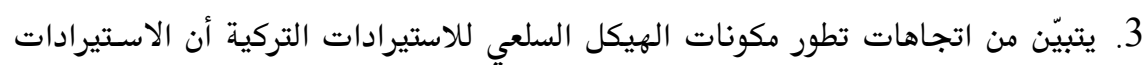

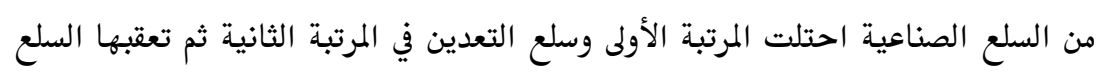

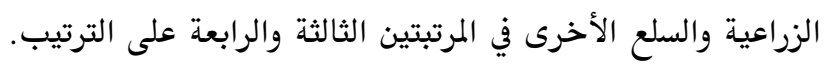



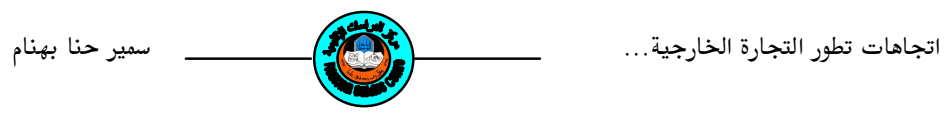

4. وجود عجز مستمر في الميزان التجاري التركي خلال مدة الدراسة 1990- 2009 بسبب تفوق قيم الاستيرادات على قيم الصادرات وعدم وجود التنوع السـلعي في هيكـل الإنتـاج

السلعي.

ثانياً: المقترحات

1. ضـرورة الاهتمـام بالقطـاع الزراعسي والسـي لزيـادة أهميتـهـ النسـبية في النـاتج المحلـي

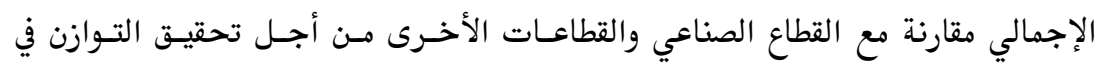

الاقتصاد التركي.

2. السعي لتخفيض العجز في الميزان التجاري بإتباع سياسة إحلال الاستيرادات الرأسماليـة

الصناعية، فضلاً عن تنوع هيكل الصادرات التركية.

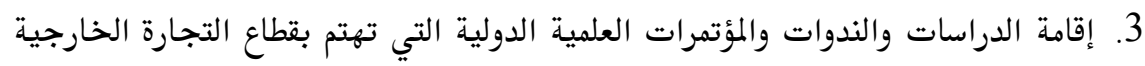

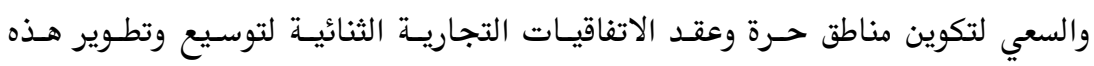

التجارة.

4. استخدام وسائل تقنية المعلومات والاتصالات في التجارة والتركيز على التجارة الالكترونية

لاختصار المسافات والوقت وتزايد تدفق السلع والخدمات.

5. ضرورة الاهتمام بالصادرات وتنويع قاعدتها والتركيز على المهمـة منهـا في تكـوين النـاتج

المحلي الإجمالي.

6. تشجيع القطاع الخاص للاستثمار في المشاريع الإنتاجية وإقامة المشاريع الزراعية.

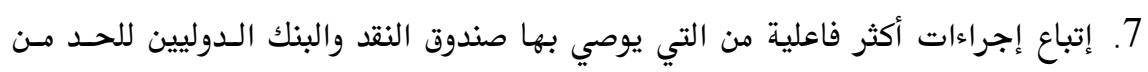

نمو الاستيرادات الاستهلاكية والكمالية .

8. ضرورة الاعتماد على الذات للحصول على تمويل بـرامج التنميـة والتخلي عـن الاعتمـاد

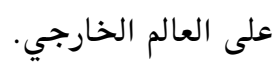




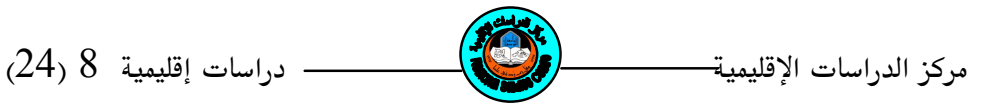

\title{
Trends in the evolution of Turkish foreign trade and its impact on economic growth for the period
}

(1990 - 2009)

\author{
H. QAamer Hanna Öchnam \\ Ossistant Electurer, Department of Economics, Gallege of \\ administration and Eeconomics, Qtmiversily of Mrosul
}

\begin{abstract}
Foreign trade is the base engine for economic growth for countries in the world, whether developed or developing, it has expanded among those countries, especially after the emergence of economic blocs and the World Trade Organization, where you can not be isolated from each other in two essential aspects: first, export the surplus production of capital goods, intermediate and primary and consumer goods to other countries, and import of capital goods and intermediate to contribute to the economic growth of the Section of them, as well as the importation of consumer goods for the needs of the growing domestic demand, including especially the developing countries, as the research aims to identify trends in the evolution of Turkish foreign trade and economic growth during the period (1990 2009), based on the research hypothesis that there is evolution in the foreign trade total Turkish as well as on the evolution of components of the Commodity Structure of Foreign Trade of Turkey as a structure exports, particularly manufactured goods and the structure of imports particularly of capital goods and agricultural and industrial, has been the adoption of the method of analysis of descriptive and quantitative through the collection and tabulation of data and information on Turkish foreign trade by relying on official sources.
\end{abstract}




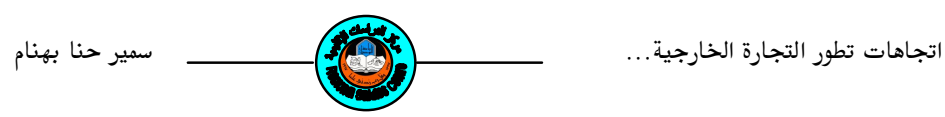

Key words: foreign trade, economic growth, exports, imports, gross domestic product.

المصادر والهوامش

(1) D.R. Appleyard and Athers, 2006, International Economics, Mc GrawHill Irwin, New York, fifth edition, p 204.

(2) www. org. com. pdf .

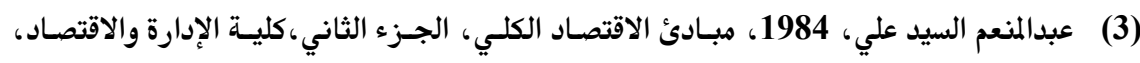

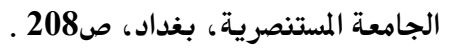

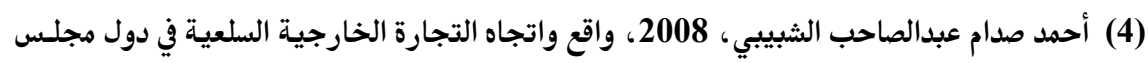

$$
\begin{aligned}
& \text { التعاون الخليجي، مجلة بحوث اقتصادية عربية، العددان 43- 44، ص صل } 73 \text { ـ. }
\end{aligned}
$$

(5) www. ibis online. net.

مريم حسن محمد الحامدي، 2009، تجـارة ليبيـا الخارجيـة مـع دول الاتحـاد الأوربي ايطاليـا

خلال لفترة 1965- 1995، بحث مستل من رسالة ماجستير، أكاديمية الدراسـات العليـا، كليـة الادية

$$
\text { العلوم الإدارية والمالية ، ليبيا. }
$$

(7) B. Balassa, 1984, Trade Between Developed and Developing countries, the decade ahead, www. oecd. org .pdf.

(8) H. Hesse, 2007, Export Diversification and Economic Growth, Yale University, International Monetary Fund.

$$
\begin{aligned}
& \text { (9) طالـب محمـد عـوض، التجـارة الدوليـة، نظريـات وسياسـات، 1995، ط1، لدار النشـر معهـد } \\
& \text { الدراسات المعرفية، عمان، الأردن. } \\
& \text { (10) موسى سعيد مطر، باسم اللوزي، 2001، التجارة الخارجيـة، طان، الدار، دار صفاء للنشـر والتوزيع، } \\
& \text { عمان، الأردن . }
\end{aligned}
$$

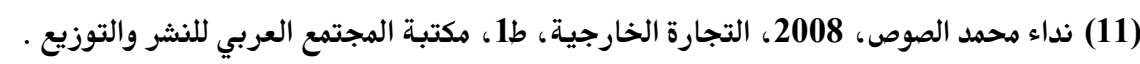

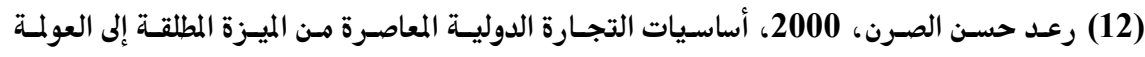

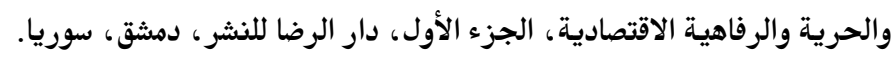




$$
\text { دراسات إقليمية } 8 \text { (24) }
$$

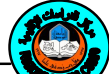

مركز الدراسات الإقليميت-

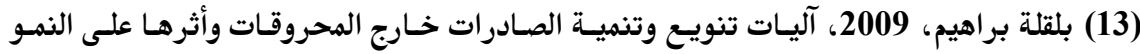

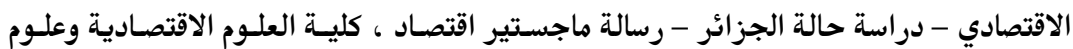

$$
\text { التسيير ، جامعة الجزائر ، الجزائر. }
$$

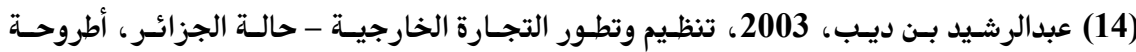

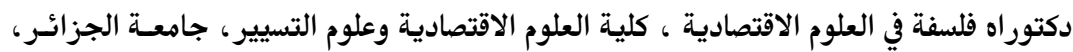

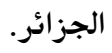

(15) سعد محمود خليل الكواز، 1995، هيكل الاستيرادات وأثره على نمو وتطور القطاعـات السلعية

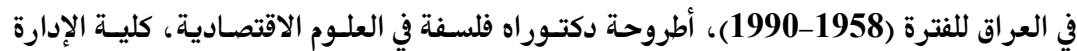

$$
\text { والاقتصاد-جامعة الموصل . }
$$

(16) D.B. David and D. H. Papell , 1997, Internatioal Trade and Structural Change, journal of international economics, vol 43, issue, 3-4. www.nber. org. pdf .

(17) نـدى سـهيل سطام الـدليمي، 2004، اليـورو ومستقبله في التجـارة الخارجيـة لـدول الاتحساد

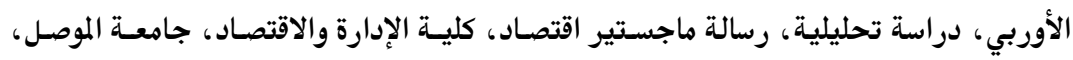

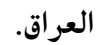

(18) - تأخذ المعادلة الصيغة الآتية :

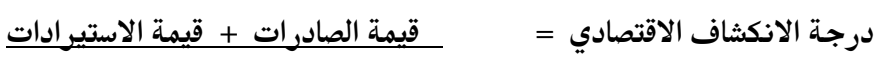

الناتج المحلي إلا جمالي

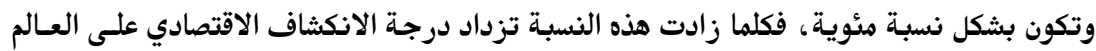

$$
\text { الخارجي والعكس صحيح. }
$$

(19) B. Balassa, 1982, Trends in international trade in manufactured goods and Structural Change in industrial countries, www. oecd. org. pdf.

(20) j. Balaguer and M.Cantavella, jorda, 2002, Structural Change in Exports and Economic Growth: Cointegration and Causality Analysis for Spain (1961-2000) www.ivie.es.pdf.

(21) هاشم محمد رشيد الزيباري، 2006، الهيكل التنظيمي لتجارة تركيا مع الاتحاد الأوربي وأثثره

في النمو الاقتصادي للمدة (1980-2004)، رسالة ماجستير في العلوم الاقتصادية الإية، كليـة الإدارة 


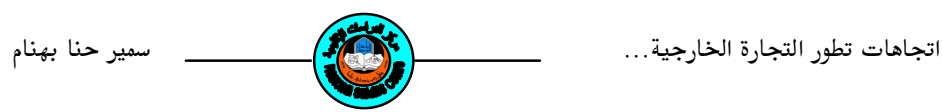

$$
\begin{aligned}
& \text { درجة التركيز السلعي للصادرات أهم السلع المصدرة } \\
& \text { إجمالي الصادرات } \\
& \text { وتكون بشكل نسبة مئوية. } \\
& \text { (23) محمد صالح تركي القريشي، فواز جـاراله الدليمي، 1990، 1990، مقدمسة في الاقتصاد الدولي، كليـة } \\
& \text { الإدارة والاقتصاد، جامعة الموصل، العراق. }
\end{aligned}
$$

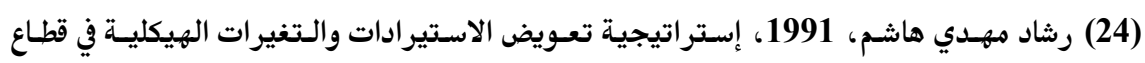

$$
\begin{aligned}
& \text { الصناعة التحويلية التركية للمدة ( 1968-1988)، مجلة دراسات تركية، العدد 2، العراق. }
\end{aligned}
$$

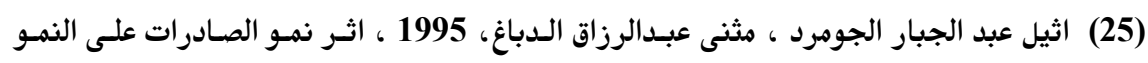

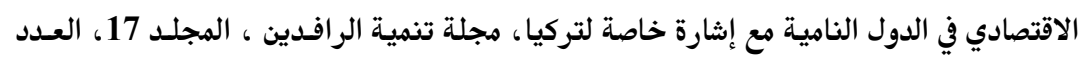

$$
\begin{aligned}
& \text { 46، كلية الإدارة والاقتصاد، جامعة الموصل، العراق. }
\end{aligned}
$$

(26) Republic of Turkish , 2010 .

(27) Turkish economy, 2010 .

$$
\begin{aligned}
& \text { (28) ويكييديا، 2010، الموسوعة الحرة، تركيا. } \\
& \text { (29) (28) (20) } \\
& \text { (30) غـازي صـالح محمـد الطـائي، 1999، الاقتصـاد الدولي، دار الكتب للطباعـة والنشر، جامعـة }
\end{aligned}
$$

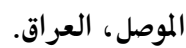

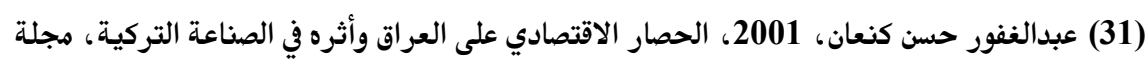

$$
\begin{aligned}
& \text { تنمية الرافدين، المجلد 2، العدد 64، كلية الإدارة والاقتصاد، جامعة الموصل، العراق. }
\end{aligned}
$$

(32) J. Howard, 2004, Free Trade and Economic Development, center for international private enterprise, C I P E. www.cipe-Arabia. org. pdf .

$$
\begin{aligned}
& \text { (33) عبدالهادي الرفاعي وآخرون، 2005، تحليل واقع التجارة الخارجيسة السورية للفترة (1990- }
\end{aligned}
$$

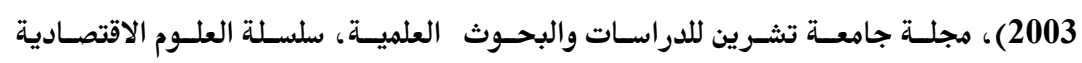

$$
\begin{aligned}
& \text { والقانونية، المجلد (27) العدد لا، سوريا. }
\end{aligned}
$$

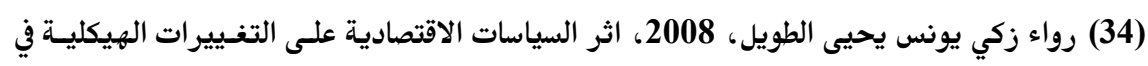

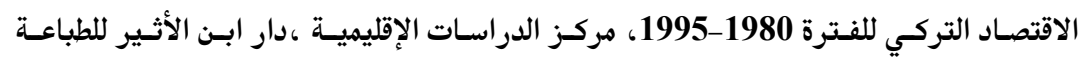

$$
\begin{aligned}
& \text { والنشر، جامعة الموصل، العراق . }
\end{aligned}
$$

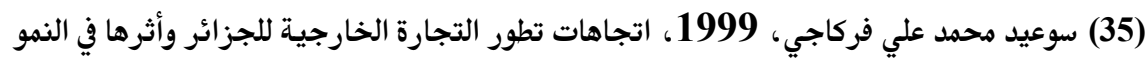

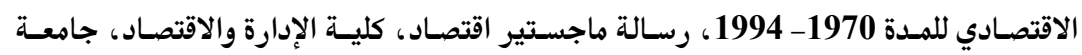

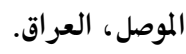


(36) طه يونس حمـادي، 1985، اثر استيرادات السلع الوسيطة على النهـو وتطور قطاع الصسناعة

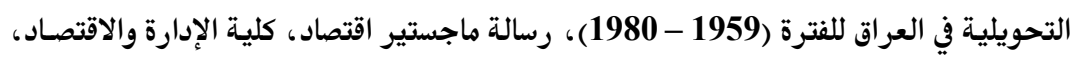

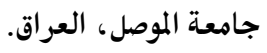

(37) عبدالحميد سليمان ظاهر، 1996، اثر الصادرات المصنعة في النمو الاقتصادي لبلدان نامية مختارة

للفترة 1952 - 1990، أطروحة دكتوراه فلسفة في العلوم الاقتصادية، كليسة الإدارة والاقتصاد، العادئ

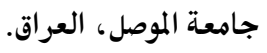

(38) احمد الكواز، 2008، التجـارة الخارجيسة و النمسو الاقتصـادي، سلسـلة جسر التنميـة، المعهـد

$$
\text { العربي للتخطيط، العدد 73، السنة السابعة، الكويت. }
$$

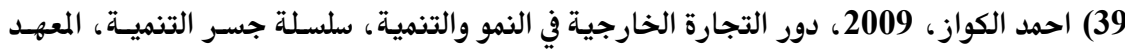

www.arab-api.org.pdf. العربي للتخطيط بالكويت.

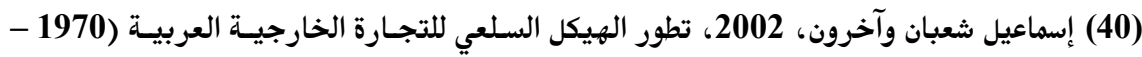

2000 )، مجلة جامعة تشرين للدراسات والبحوث العلمية، سلسلة العلوم الاقتصادية، المجلد الديد

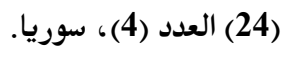

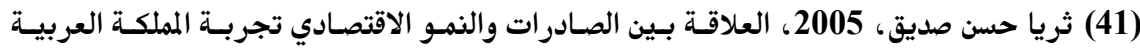

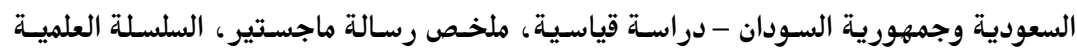

لجمعية الاقتصاد السعودية، المجلد السادس، العدد الحادي عشر، كلية العلوم الإدارية، جامعة السية

$$
\text { الملك سعود، السعودية. }
$$

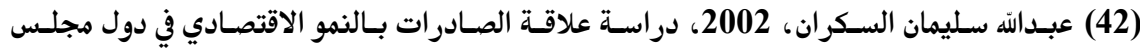

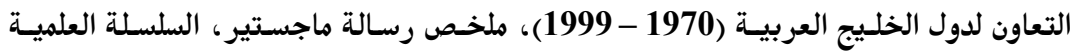

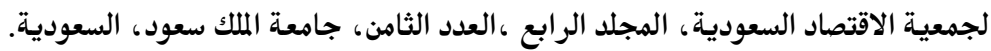

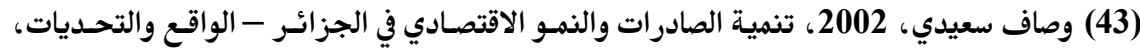
مجلة الباحث، العدد الأول، جامعة ورقلة، الجزائر.

(44) United Nations, 2005, Trade And Development Report, Conference

On Trade And Development Geneva united Nations, New York and

Geneva.

(45) International Monetary Fund, 2007, 2008, 2009.

(46) State institute of statistics (sis), 2009.

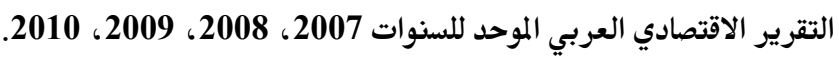

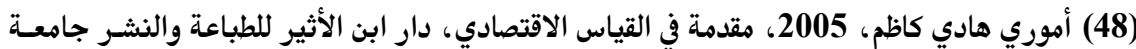

الموصل، كلية الإدارة والاقتصاد، جامعة بغداد، العراق. 


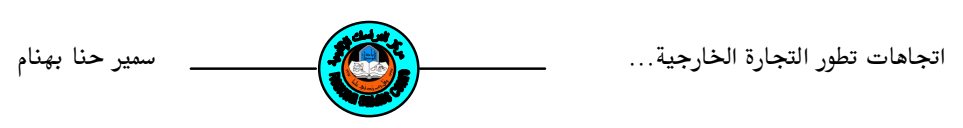

(49) حسين علي بخيت، سحر فتح الهه، 2002، مقدمة في الاقتصاد القياسي، الدار الجامعيـة للطباعـة

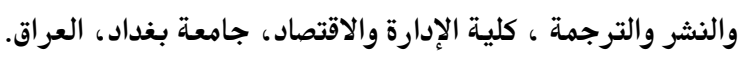

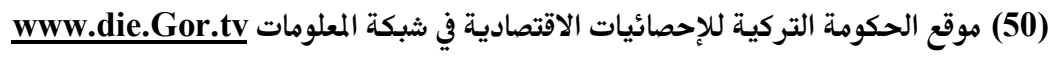

